NBER WORKING PAPER SERIES

GLOBAL CRISES AND EQUITY MARKET CONTAGION

\author{
Geert Bekaert \\ Michael Ehrmann \\ Marcel Fratzscher \\ Arnaud J. Mehl \\ Working Paper 17121 \\ http://www.nber.org/papers/w17121 \\ NATIONAL BUREAU OF ECONOMIC RESEARCH \\ 1050 Massachusetts Avenue \\ Cambridge, MA 02138 \\ June 2011
}

We would like to thank Mardi Dungey, Andy Rose and Shang-Jin Wei for discussions and suggestions as well as participants at seminars or conferences at the Hong Kong Monetary Authority, National Bank of Serbia, Bank of England, Banco Central do Brasil, CESifo, Tsinghua-Columbia Workshop in International Economics, Banque de France-CEPR workshop on macroeconomics of global interdependence (Paris, 2012), Q-Group, (Tampa, 2012), EMG-ESRC Workshop on Global Linkages and Financial Crises (Cass Business School, London, 2012) for comments on earlier versions of the paper, as well as Assaf Shtauber and Tadios Tewolde for helpful research assistance. The views expressed in this paper are solely our own and do not necessarily reflect those of the European Central Bank or the National Bureau of Economic Research.

NBER working papers are circulated for discussion and comment purposes. They have not been peerreviewed or been subject to the review by the NBER Board of Directors that accompanies official NBER publications.

(C) 2011 by Geert Bekaert, Michael Ehrmann, Marcel Fratzscher, and Arnaud J. Mehl. All rights reserved. Short sections of text, not to exceed two paragraphs, may be quoted without explicit permission provided that full credit, including (C) notice, is given to the source. 
Global Crises and Equity Market Contagion

Geert Bekaert, Michael Ehrmann, Marcel Fratzscher, and Arnaud J. Mehl

NBER Working Paper No. 17121

June 2011, Revised June 2012

JEL No. G01,G15

\begin{abstract}
$\underline{\text { ABSTRACT }}$
Using the 2007-09 financial crisis as a laboratory, we analyze the transmission of crises to country-industry equity portfolios in 55 countries. We use a factor model to predict crisis returns, defining unexplained increases in factor loadings and residual correlations as indicative of contagion. We find statistically significant evidence of contagion from US markets and from the global financial sector, but the effects are economically small. By contrast, there has been substantial contagion from domestic equity markets to individual domestic equity portfolios, with its severity inversely related to the quality of countries' economic fundamentals and policies. This confirms the old "wake-up call" hypothesis, with markets and investors focusing substantially more on country-specific characteristics during the crisis.

\author{
Graduate School of Business \\ Columbia University \\ 3022 Broadway, 411 Uris Hall \\ New York, NY 10027 \\ and NBER \\ gb241@columbia.edu \\ Michael Ehrmann \\ European Central Bank \\ Postfach 160319 \\ D-60066 Frankfurt am Main \\ GERMANY \\ michael.ehrmann@ecb.int
}

Geert Bekaert

\author{
Marcel Fratzscher \\ European Central Bank \\ Kaiserstrasse 29 \\ D-60311 Frankfurt/Main GERMANY \\ marcel.fratzscher@ecb.int
}

\author{
Arnaud J. Mehl \\ European Central Bank \\ Kaiserstrasse 29 \\ 60311 Frankfurt \\ Germany \\ Arnaud.Mehl@ecb.int
}


Ever since the seminal work of King and Wadhwani (1990) following the global October 1987 stock market crash, the international finance literature has studied how shocks are transmitted across borders. Words with negative connotations such as "volatility spillovers" (e.g. Engle, Ito and Lin (1990); Masulis, Hamao and Ng (1990)) and “contagion” have been coined to indicate shock transmission that cannot be explained by fundamentals or co-movements that are viewed as "excessive." Countless papers have been written proposing quantitative measures of contagion (see Karolyi (2003), Dungey et al. (2004) for surveys) or developing theories to explain it (e.g. Allen and Gale, 2000).

The financial crisis of 2007-09 has arguably been the first truly major global crisis since the Great Depression of 1929-32. While the crisis initially had its origin in the United States in a relatively small segment of the lending market, the sub-prime mortgage market, it rapidly spread across virtually all economies, both advanced and emerging, as well as across economic sectors. It also affected equity markets worldwide, with many countries experiencing even sharper equity market crashes than the United States, making it an ideal laboratory to revisit the debate about the presence and sources of “contagion” in equity markets.

This article studies how and why the crisis spread so violently across countries and economic sectors. We develop a three-factor model to set a benchmark for what global equity market comovements should expected to be, based on existing fundamentals. This model distinguishes between a US-specific factor, a global financial factor and a domestic factor for the pricing of 415 country-sector equity portfolios across 55 countries worldwide. We define contagion as the co-movement in excess of that implied by the factor model. This contrasts with many contagion articles simply comparing comovements before and during the crisis. Obviously, our benchmark factor model, which we term the interdependence model, implies transmission of shocks proportional to the factor exposures, as measured pre-crisis. Excess comovements relative to the model can arise in four different ways leading to four distinct types of contagion. ${ }^{1}$ The first three involve factor exposures increasing unexpectedly in the crisis. Contagion stemming from the US or from the global financial sector, which we label "US contagion" and "global contagion”, implies a rise in the co-movement of domestic sector portfolios with the US or global factors, respectively. Alternatively, the exposures relative to the domestic factor may increase, raising the co-movement of portfolios within a country during the crisis, relative to the 
factor model predictions. We call this phenomenom “domestic contagion”. Finally, returns unrelated to the factors may still be correlated across stocks during the crisis, which we call residual contagion.

We indeed find significant evidence of contagion during the 2007-09 financial crisis. Yet, while the interdependence model is strongly rejected in a statistical sense, it nonetheless explains a substantial fraction of return variation during the crisis. Second, we find on average statistically significant but economically small evidence of contagion from US markets and the global financial sector. By contrast, we find strong evidence of domestic contagion, with factor loadings with respect to the domestic factor portfolio increasing on average by $50 \%$. Interestingly, there is no evidence that domestic contagion played a role in past crises, such as the 1998 LTCM crisis or the 2000-02 bust of the TMT bubble. Importantly, we observe a high degree of heterogeneity in contagion across country-sector equity portfolios, with the contagion parameters and pre-crisis U.S. and global banking sector factor exposures being negatively correlated.

We further use our framework to disentangle the channels of contagion and to explain the heterogeneity in contagion across portfolios by testing whether and how the dependence of factor exposures on various instruments changes during the crisis. We examine 6 different categories of channels. First, as the crisis originated in the banking sector, we examine international banking sector links at the country level, and firm-specific characteristics measuring the degree of financing constraints and interest rate exposure. We also study the role of various financial policies introduced during the crisis to protect the domestic financial sector, and in particular domestic banks (through debt and deposit guarantees and capital injections) which, in essence, transferred risk on a massive scale from individual firms to governments.

Second, we examine the "globalization hypothesis" which implies that crises hit hardest those economies that are highly integrated globally, such as through trade and financial linkages. The globalization process may have gradually increased the US and global banking sector factor exposures over time (see Bekaert and Harvey,1997; Baele, 2005) but may also have led to decoupling during the crisis, as globalization reversed.

Third, information asymmetries may decrease during crises, as investors focus on easily available public information, which may in turn increase correlations. Fourth, the "wake-up call 
hypothesis” states that a crisis initially restricted to one market segment or country provides new information that may prompt investors to reassess the vulnerability of other market segments or countries, which spreads the crisis across markets and borders (Goldstein, 1998; Masson, 1999; Goldstein, Kaminsky and Reinhart, 2000). ${ }^{2}$ Under this hypothesis, domestic fundamentals are likely to play a dominant role in the transmission of the crisis. Finally, contagion may occur without discrimination at all, driven by herding behavior or investors' risk appetite beyond the effect of fundamentals, prompting us to examine the role of global risk and liquidity indicators.

We strongly reject the globalization hypothesis. Only an overall measure of financial integration explains an economically important part of the contagion evidence, but more financially integrated countries experienced less contagion, not more contagion, from the US market. Banking sector links and information flow variables also do not explain the variation in contagion across portfolios. Instead, we find that countries with high political risk, large current account deficits, large unemployment and high government budget deficits, experienced a high degree of contagion. We also find that the introduction of debt and deposit guarantees during the crisis helped insulate domestic equity markets to an economically and statistically significant extent from the impact of the crisis through reducing the exposures to global, US and domestic factors. Hence, the wake-up call hypothesis and domestic banking policies are the main sources of the domestic contagion phenomenon that we document.

Our work contributes mainly to two literatures. First, there is the vast literature on international market integration, shock transmission and contagion. Our approach does not suffer from the volatility bias described in the seminal work of Forbes and Rigobon (2002), and owes most to the factor model approach in Bekaert, Harvey and Ng (2005), who also define contagion as excessive co-movement over and above the predictions of a factor model. What we add is a detailed analysis of the sources of contagion, allowing us to differentiate several economic hypotheses regarding contagion.

Second, our work relates to the growing literature on the 2007-09 global financial crisis. This includes articles focusing on the drivers of transmission of the crisis across firms and markets within the US, such as Tong and Wei (2010), Almeida et al. (2009) and Diebold and Yilmaz (2010), or articles 
taking a more macroeconomic perspective such as Eichengreen et al. (2009), Frankel and Saravelos (2010) and Rose and Spiegel (2010, 2011). There are a few contemporaneous articles also focusing on equity market contagion. For instance, Tong and Wei (2011) find that the average decline in stock prices during the crisis in a sample of 4000 firms in 24 emerging countries was more severe for those firms intrinsically more dependent on external finance (in particular on bank lending and portfolio flows). Hau and Lai (2011) show that stocks with a high share of equity funds ownership performed relatively well during the crisis, whereas stocks with ownership links to funds that were heavily affected by portfolio losses in financial stocks severely underperform. In a related vein, Stulz and Beltratti (2009) investigate whether the variation in the cross-section of stock returns of large banks across the world during the crisis is related to bank-level governance, country-level governance, country-level regulation, as well as to bank balance sheet and profitability characteristics before the crisis. Finally, Calomiris, Love and Martinez Peria (2010) show that credit supply stocks, global demand shocks and selling pressures in the equity market had a significant negative effect on individual stock returns during the 2007-2008 crisis but had no such effects during an earlier placebo period.

The paper is organized as follows. The first section presents the empirical framework, defining and distinguishing between interdependence and contagion. Section II contains the empirical findings, first contrasting how a pure interdependence model fares relative to a model accommodating contagion before analyzing the channels of contagion. Section III summarizes the findings and concludes.

\section{Empirical framework}

This section outlines the model we estimate, contrasts the concepts of interdependence and contagion and discusses estimation issues.

\section{A. The factor model}

We formulate an international factor model with three factors, a US factor, a global financial factor, and

a domestic market factor, $F_{t}{ }^{\prime}=\left[R_{t}^{U}, R_{t}^{G}, R_{t}^{D}\right]$. The three factors are value-weighted market indices, so that the model potentially embeds different CAPMs as special cases: when the betas on the first two 
factors are zero, the model becomes a domestic CAPM; when the beta of the domestic factor is set to zero, the model can act as a World CAPM. As in any factor model, the correlation between portfolios is increasing in the factor exposures of the portfolios and the magnitude of the factor volatilities. The use of these three factors, including a domestic factor, ensures that the model satisfactorily fits comovements across our portfolios in normal times. ${ }^{3}$ The model then allows studying whether the 2007-09 global crisis mainly reflected a global financial shock, a shock specific to the US economy that subsequently spread globally, or to what extent there was an element of increased vulnerability at the country or firm level that spread the crisis.

The full model looks as follows:

$$
\begin{aligned}
& R_{i, t}=E_{t-1}\left[R_{i, t}\right]+\beta_{i, t}{ }^{\prime} F_{t}+\eta_{i, t} C R_{t}+e_{i, t} \\
& \beta_{i, t}=\beta_{i, 0}+\beta_{1}^{\prime} Z_{i, t-k}+\gamma_{i, t} C R_{t} \\
& \gamma_{i, t}=\gamma_{i, 0}+\gamma_{1}^{\prime} Z_{i, t-k} \\
& \eta_{i, t}=\eta_{i, 0}+\eta_{1}{ }^{\prime} Z_{i, t-k}
\end{aligned}
$$

where $R_{i, t}$ is the excess return of portfolio $i$ during week $t$ (i.e., the return less the three month US T-bill rate in weekly units), $E_{t-1}\left[R_{i, t}\right]$ is the expected excess return, measured as a linear function of the lagged excess return and the local dividend yield, $F_{t}$ is the vector of the three observable factors, $C R_{t}$ a crisis dummy, and $Z_{i, t}$ a vector of control variables, designed to capture time and cross-sectional variation in factor exposures. These variables may be portfolio or country-specific, and are typically lagged by two quarters. If the dimension of $Z$ is $K$, the matrices $\beta_{1}, \gamma_{1}$ and $\eta_{1}$ are $K \times 3$. The sample period is 1 January 1995 to 15 March 2009, i.e. it ends with the trough of the global equity market during the crisis. The sample contains about 725 weekly observations for our 415 country-sector equity portfolios. We define the financial crisis to begin on 7 August 2007, but later report a robustness analysis using the collapse of Lehman Brothers on 15 September 2008 as an alternative starting point.

Each portfolio $i$ reflects a country-sector portfolio, measured as the value-weighted returns of all stocks in a particular sector of a particular country at time $t$. To avoid adding-up constraints and spurious correlations, the $\mathrm{R}_{\mathrm{t}}^{\mathrm{D}}$ factor is value-weighted across country-sector portfolios located in the 
same country as portfolio $i$, but excludes returns of portfolio $i$ itself. Strictly speaking, we would therefore need to denote domestic returns by $\mathrm{R}_{\mathrm{t}}^{\mathrm{Dli}}$, but use the shortcut for notational ease. All returns are measured in US dollars. ${ }^{4}$ In order to obtain an intuitive interpretation of the estimates of the factor loadings, we orthogonalize the three factors. The global factor is orthogonalized by regressing global financial sector returns on US returns over the full sample period (including the crisis period) and then using the residuals of this regression as the global factor. ${ }^{5}$ Similarly, following Bekaert, Hodrick and Zhang (2009), we extract a domestic return component which is orthogonal to those of both the US factor and the global factor by regressing each domestic market return on US returns and global financial sector returns, and then using the residual of this regression as the domestic factor. ${ }^{6}$

\section{A. 1. Interdependence versus contagion}

When $C R_{t}$ is eliminated from the model for all $t$, we refer to it as the "interdependence model". Each portfolio's risk exposure is then captured by three (potentially time-varying) factor loadings. Under the null of this model, the co-movement ("interdependence”) between the various portfolios is determined by the factor exposures (the betas) and the variance covariance matrix of the factors. With orthogonal factors, such a model can potentially fit the observed increase in correlations during the crisis through an increase in factor volatilities. This is true because the correlation between a portfolio and a factor is then the beta with respect to that factor, times the ratio of factor to portfolio volatility, which can be shown to be increasing in the factor's volatility. As volatilities tend to dramatically increase during crises, increased correlations are thus not necessarily indicative of "contagion,” an intuition formalized by Forbes and Rigobon (2002). To explain the crisis incidence across portfolios, portfolios with high betas according to the model should decrease the most during the crisis. If this model fails to explain the crisis incidence and under-predicts portfolio correlations, we uncover contagion. By focusing on deviations from a reduced-form factor model, we avoid the volatility bias described in Forbes and Rigobon (2002) and contagion only reflects “unexpected” comovements relative to a factor model, consistent with the contagion definition in Bekaert, Harvey and $\mathrm{Ng}$ (2005). The introduction of the 
crisis dummy to Equations (1) and (2) allows us to uncover the sources of contagion through the various $\gamma$ or $\eta$ coefficients.

First, $\eta$ in equation (1) captures contagion unrelated to the observable factors $F_{t}$ of the model. If $\eta$ is substantially negative for a sub-set of stocks, these stocks show excess comovement during the crisis. Our $\eta$ coefficients potentially capture "non-fundamental” contagion, such as herd behavior where investors stop discriminating across firms and countries based on economic fundamentals. However, there are also rational stories of "investor contagion.” During a financial crisis, investors may face margin calls and/or may need to raise liquidity, which may transmit shocks from one country to another. Kodres and Pritsker (2002) develop a model where portfolio rebalancing creates "rational contagion,” the severity of which depends on shared macro-risk factors and the information asymmetry in each market. Kyle and Xiong (2001) focus on losses by arbitragers which may lead to liquidations in several markets, thus inducing contagion. While we do not provide a formal test of these models, we consider some instruments related to risk aversion that may be informative about these channels.

Second, $\gamma$ in equation (2) measures contagion via the factors $F_{t}$, i.e. changes in interdependence during the crisis. Positive $\gamma$ 's imply increased correlations of portfolios with the factors and across portfolios in the crisis relative to tranquil periods. Such contagion may be induced either by an unconditional increase in the factor loadings $\left(\gamma_{i, 0}\right)$ or an increase in the factor loadings conditional on a number of possible determinants $Z_{i, t}\left(\gamma_{1}\right)$. The strength and novelty of this approach is that it allows us to identify the origin of contagion (US, global, or domestic) and the transmission channels, which we now discuss in detail.

\section{A.2. Instruments to model time variation in exposures}

Equations (2) to (4) contain a set of lagged instruments, $Z_{i, t-k}$, which are used to model the time variation in the exposures $(\beta, \gamma, \eta)$. This practice has a long tradition in finance; see, for example, Ferson and Harvey (1991). ${ }^{7}$ We entertain a large number of potential instruments, which are listed in Table I, and divide them into six different categories in order to distinguish between different channels and hypotheses. Along the way, we surmise various sources of domestic contagion. 
The first category uses various proxies to investigate the importance of the banking sector as a transmission channel across equity markets. For that purpose, we investigate consolidated foreign claims of the domestic banking sector, either vis-à-vis banks in the US or in all other countries, the growth of credit to the private sector and various measures for the dependence of firms on external financing, in particular through banks (interest rate exposure, size and financial constraints).

Allen and Gale (2000) construct a bank run model where liquidity shocks cause the default of a leveraged lender, which in turn leads to losses for banks lending to this institution, causing a potential domino effect. In the contagion literature, a number of authors have stressed the "common creditor problem" where countries linked to banks (through claims or liabilities) that have claims on countries in crisis may suffer contagion that extends to their equity markets (see Van Rijckeghem and Weder, 2001, Kaminsky and Reinhart, 2000, Tong and Wei (2010, 2011); Caramazza et al., 2004). In the context of the global crisis, the liquidity and solvency problems of the US banks were rapidly transmitted to other international financial institutions, either because of money market links, direct exposure, or the exposure to toxic assets. The data of the BIS measure the extent of claims local banks have to, respectively, US banks or any international banks through deposits, loans or other assets. Such exposure has a direct effect on the local banking sector and indirect effects on other stocks. It is conceivable that the extent of the exposure is also commensurate to the extent to which local banks have (over) extended credit to the private sector, as deleveraging during the crisis may adversely affectdomestic borrowers’ ability to obtain funding. Finally, we would expect the effect of banking problems to be particularly severe for firms with financing constraints and for firms with more interest rate exposure, as they may have shorter maturity debt and thus face steeper refinancing costs. For instance, Almeida et al. (2009) find that firms with large portions of long-term debt maturing at the time of the crisis reduced investment significantly more than similar firms that did not need to refinance their debt during the crisis. We use the financial constraints measured purposed in Whited and Whu (2006) and compute interest rate exposure using a regression procedure. We refer to the appendix for more details on the computation of these variables. Small firms tend to rely more on bank financing than large firms prompting us to also use the log of total assets as an instrument. Banking sector links are a potential but perhaps unlikely source of domestic contagion. For example, it is possible that exposures to the 
domestic factor return are increasing in international bank linkages if most firms in the economy are indeed dependent on bank financing and banks in the economy have international links. If we control for such linkages, we should not find contagion in the crisis. Yet, it is possible that for countries with banks that are disproportionally affected by the crisis, and where local bank dependence is large, we may pick up some domestic contagion through a banking sector effect.

As a second category of instruments, we collected data on three country-specific policy responses to the crises (listed under "banking policy”), namely capital injections in both financial and non-financial firms (though these are primarily banks), as well as new or extended deposit guarantees and debt guarantees for banks. ${ }^{8}$ A key feature that we exploit for this analysis is that not all countries implemented such policies, that there are differences in the precise measures that were implemented, and in the timing of their announcement. We define dummy variables that take the value of one for the period after the announcements of the various policies, and for the full period of their existence. ${ }^{9}$ This raises three caveats. First, official announcements of such financial policies may have been preceded by rumors or concrete indications that a government considers such policy measures, thus having a market effect even before an announcement is made. A second issue is that such policies may in part be endogenous to the crisis itself, i.e. they were implemented in response to the crisis hitting a particular country particularly hard. While we cannot resolve this potential endogeneity bias, we note that it should make it harder to prove in the data that such policies are associated with a smaller decline in equity markets. Third, it could be the case that the introduction of these policies might have had longerlasting (and potentially adverse) effects on stock market performance beyond the time span analyzed in this paper, in particular during the European sovereign debt crisis. Such an analysis is beyond the scope of the current paper. Our hypothesis is that these policy responses have helped countries and individual firms within a country to be more insulated and overall less affected by the crisis, thereby reducing the magnitude of contagion, both from foreign markets and across sectors within a country.

The third set of variables measures external exposure through trade and financial openness. A great many researchers have pointed out the increased vulnerability to crises that comes with financial and economic integration (see Mendoza and Quadrini (2010) for a theoretical analysis, and Fratzscher (2012) for empirical evidence during the 2007-09 crisis). The trade channel in particular has often been 
associated with international spillovers and contagion (see Forbes (2004), Kaminsky and Reinhart (2000), Caramazza et al. (2004)). As discussed in Baele and Inghelbrecht (2009), trends in market integration make it necessary to let interdependence coefficients depend on openness indicators to properly test for contagion in a crisis, as average beta coefficients may underestimate the global exposures just before the crisis. We use exports plus imports to measure trade openness. Financial integration with the rest of the world is measured using the stock of international portfolio assets and liabilities; or financial depth (measured as the size of the domestic equity market capitalization), which has been shown to correlate with financial openness (see, e.g. Bekaert and Harvey, 1995). Broner, Gelos and Reinhart (2006), and Boyer, Kumagai, and Yuan (2006) stress how portfolio holdings of international investors in various countries and their capital reallocations following negative returns, can affect the transmission of shocks. In the recent global crisis, US international funds may have retrenched from global markets, causing spillovers to be particularly severe for countries with substantial bilateral portfolio flows with the US. We therefore also use bilateral portfolio investment flows, i.e. net flows of bilateral portfolio assets and liabilities with the US, as is common in the literature (e.g. Kaminsky, Lyons and Schmukler, 2004). All the above measures are scaled by GDP. We also include exchange rate exposure, which may constitute an alternative, firm-specific source for equity market co-movements (e.g. Dumas and Solnik 1995). The methodology for measuring exchange rate exposure is outlined in Appendix B.

Trade and financial integration channels may indirectly also contribute to domestic contagion if they break down during the crisis. Suppose international factor exposures are increasing in external integration measures and domestic factor exposures are decreasing in such measures. This could arise in a partial segmentation model where international firms are priced differently from purely domestic firms, and the latter are still an important part of the domestic market portfolio. If trade and capital flows collapse in the crisis, this could cause a pattern where firms now are more correlated with the domestic factor and less with the international factors. If we do not control for this time -variation in betas, our contagion estimates may show a reduction in global and an increase in domestic betas. With the factor exposure and contagion channels depending on trade and financial integration directly, we can examine this story explicitly. 
Table I

A fourth category of instruments relates to information asymmetries which may reduce crossborder capital flows and induce home bias (e.g. Albuquerque, Bauer and Schneider, 2009, Brennan and Cao, 1997). Apart from measures of information flow, such as the amount of telephone traffic and the ratio of the value of net imports of newspapers from the US (in US dollars) to domestic GDP, we also include the most commonly used proxy of information asymmetry in the literature on capital flows, namely the geographic distance of a country to the US (Portes and Rey, 2005; Daude and Fratzscher, 2008). Dumas, Lewis and Osambela (2011) generate implications similar to those of information asymmetry models by positing that domestic and foreign investors may have differences of opinion on public signals. In particular, local investors are better equipped to "interpret” (local) public news than foreign investors are. As shown by Dumas, Lewis and Osambela (2011), in such a model returns and international capital flows co-move positively (as foreign investors view increases in the stock market, erroneously, as a signal of future increases). Following this approach, we proxy for differences in opinion using the pre-crisis (2006) correlation coefficients between the bilateral capital flows from the US to a particular destination country (as captured by the net sales of long-term US securities by domestic residents and of foreign securities to US residents), on the one hand, and the destination country’s local equity returns, on the other hand, with a higher correlation indicating a higher difference in opinion.

The fifth set of variables intends to provide a broad view of domestic macroeconomic fundamentals. With these variables, we can test what Goldstein (1998) has coined the "wake-up call" hypothesis, following the 1997-98 Asian financial crisis. During that crisis, potential risk determinants at the country level -such as the quality of economic policies and institutions- suddenly became important for investors' decisions while they were considered relatively unimportant before the crisis. This hypothesis is easily testable in our framework, as it implies that macroeconomic fundamentals that do not matter in normal times suddenly matter in crisis times, as reflected in the $\gamma_{i t}$ coefficients for our set of macro-economic indicators. The wake-up call hypothesis provides an obvious explanation of “domestic contagion.” This set of variables includes a measure of political risk from ICRG, the sovereign rating and the level of foreign exchange reserves. It also contains several macroeconomic 
indicators, namely the current account balance, the government budget balance, and the unemployment rate.

The final set of variables consists of global measures of risk aversion and liquidity which may cause "investor contagion”. Evidence is mounting that international asset prices are quite sensitive to such measures (see e.g. Bekaert, Harvey, Lundblad and Siegel, 2011; Baker, Wurgler and Yuan, 2009). The risk aversion of investors may substantially increase during the crisis, making them shun risky assets and flee into safer assets; in particular, government bonds in the US and other advanced economies. We proxy for risk aversion through the VIX index of the S\&P500. Moreover, a central element of the crisis was a freezing of credit and inter-bank markets and a liquidity squeeze that made it difficult for financial and non-financial institutions to obtain capital. Indeed, a literature is emerging that stresses the role of (il)liquidity in causing or exacerbating crises (e.g. Adrian and Shin 2010, Brunnermeier and Pedersen 2009). We use the TED spread as an indicator of illiquidity, but it of course also reflects the credit risk of banks. Note that all these risk and liquidity variables are common to all equity portfolios in the sample.

\section{B. Estimation, Specification Tests and Diagnostics}

\section{B.1. Model Estimation}

We estimate our model for all portfolios jointly by means of pooled OLS. Standard errors account for heteroskedasticity. Note that the instruments $Z_{i, t}-$ with the exception of the financial policies, as outlined above - are lagged by 2 quarters in order to prevent that an unobserved factor may influence simultaneously both returns and the fundamental $Z$ in a given period, thus generating a spurious relationship between both.

Because we have 25 instruments, an estimation of the full model will generate a large amount of insignificant regressors that needlessly inject noise into the estimated model. When estimating the full model (1)-(4) with instruments, we therefore estimate different model specifications. In a first step, we include each of the 25 instruments individually in the model. As a second step, we build on the work of David Hendry (see, for instance, Hendry and Krolzig 2005) to pare down the regression to a more manageable number of independent variables. We start out with the full model including all 25 
instruments simultaneously, and then step-by-step reduce the model by excluding the variable with the least statistically significant contagion parameter. This procedure is continued until only those instruments are left in the model that have significant contagion parameters at the $10 \%$ significance level. The aim of this "encompassing" approach is to reduce the dimensionality of the model and to arrive at a model that can be interpreted in an economically meaningful way. ${ }^{10}$

\section{B.2. Specification Tests and Diagnostics}

We now focus our attention on the fit of the model. A well-specified factor model should render all correlations between the residuals of the 415 portfolio regressions negligible. Given the dimensionality of our estimation, a formal test of such a hypothesis is rather meaningless. Instead, we test and/or diagnose excess co-movements of the residuals at the country level, the most important dimension for contagion tests.

To measure excess co-movements within countries, $i$ we now add an indicator subscript $c$, denoting country, to each portfolio. There are $N_{c}$ portfolios within country c and recall that there are 55 countries in total; so that $c$ runs from 1 to 55 . Excess co-movement within a country can occur when the factor model either systematically over or under predicts exposure to the factors for portfolios within a given country. Formally, consider:

$$
\operatorname{EXCOV}_{c, t}=\frac{2}{N_{c}\left(N_{c}-1\right)} \sum_{i=1}^{N_{c}} \sum_{j>i}^{N_{c}}\left(e_{i, c, t} \times e_{j, c, t}\right)
$$

This average covariance (across portfolios within a country) should be on average zero for all countries. To derive a formal test, we simply investigate the average across the countries:

$$
\operatorname{EXCOV}_{t}=\frac{1}{55} \sum_{c=1}^{55} E X C O V_{c, t}
$$

To create a test statistic, we must divide EXCOV by its sample variance. We use 26 Newey-West (1987) lags in computing this variance. The excess co-movement test then becomes:

$$
\text { ECTEST }=\frac{\left[(1 / T) \sum_{t=1}^{T} E_{\left.X C O V_{t}\right]^{2}}\right.}{\operatorname{VAR}\left(\operatorname{EXCOV}_{t}\right)}
$$


which is $\chi^{2}(1)$ under the null.

We also compute two diagnostic statistics that are easily comparable across different models, or across different time periods (crisis versus non-crisis). First, let $\rho_{i, j, c}$ be the correlation between the residuals of portfolios $i$ and $j$ within country $c$. Thus we compute:

$$
E X C O R=\frac{1}{55} \sum_{c=1}^{55} \frac{2}{N_{c}\left(N_{c}-1\right)} \sum_{i=1}^{N_{c}} \sum_{j>i}^{N_{c}} \rho_{i, j, c}
$$

Second, the ECTEST averages the country-specific co-movements of residuals across all countries. It is conceivable that strong rejections in a few countries may not result in a rejection of the null. To better diagnose the performance of various models, we also compute the following country-level excess comovement diagnostic:

$$
E C D I A G=\sum_{c=1}^{55} \frac{\left[(1 / T) \sum_{t=1}^{T} E X C O V_{c, t}\right]^{2}}{\operatorname{VAR}\left(\operatorname{EXCOV}_{c, t}\right)}
$$

where the time series variance is again computed with 26 Newey-West lags. If the country-specific test statistics are independent, ECDIAG would have a $\chi^{2}(55)$ distribution. However, we use the statistic to compare alternative models and alternative periods.

To further analyze the performance of the model(s), we conduct three additional diagnostic exercises, which are described in more detail below. First, we compare actual returns with the predicted returns under various versions of the factor model during the crisis. Second, we compare the average actual increase in correlations with the factor returns during the crisis with the increase generated by the factor model. Recall that in the factor model, such an increase occurs when the volatility of the factors increases or factor exposures increase. Third, we perform a variance decomposition of returns to contrast the relative economic importance of interdependence versus contagion during the crisis and their various components

\section{Empirical Results}

Our modeling strategy is to first investigate the presence of interdependence versus contagion in subsections $\mathrm{A}$ and $\mathrm{B}$, before turning to the channels of interdependence and contagion in sub-section $\mathrm{C}$. It 
turns out that allowing for time-variation in the betas does not affect our inference about contagion, but the cross-sectional variation in the instruments does help explain the cross-country incidence of the crisis.

\section{A. Interdependence}

Our extended factor model (1)-(4) with crisis interactions and contagion may not be necessary to explain the transmission of the financial crisis in 2007-09. If the original factor model without contagion parameters correctly anticipates the systematic risks of the various portfolios, portfolios with larger (smaller) exposures to the US and global financial sector portfolios should witness the steepest (smallest) valuation declines during the crisis. To explore this possibility, we estimate the following simple variant of our three-factor model:

$$
R_{i, t}=E_{t-1}\left[R_{i, t}\right]+\beta_{i, 0}{ }^{\prime} F_{t}+e_{i, t}
$$

with all variables defined as before, and including the same three factors - a US factor, a global financial factor, and a domestic market factor. Table II reports the betas and displays the specification tests. The specification test ECTEST should be $\chi^{2}(1)$ under the null, and rejects very strongly the null of no excess country-specific residual comovements, both across the full sample and in the crisis. Note that it is conceivable that the test has much less power during the shorter crisis period than over the full sample; yet the average within-country residual correlation is also similar across the two periods. Including the crisis period in the estimation tends to slightly increase the betas, which helps improve the fit within the crisis period and worsens it outside the crisis period. The ECDIAG test statistic is a whopping 618 over the full sample period and 482 over the crisis period. The $1 \%$ critical value for a $\chi^{2}(55)$ is 94.42 , but of course the various country statistics are not independent and are likely positively correlated.

\section{Tables II - III}

The betas reported are equally weighted averages across all 415 portfolios, with the standard error also reflecting the covariance between the individual estimates. Economically, the exposure to the three factors is not very different on average. It may be surprising that the exposure to the global 
banking sector is so large. However, if country factors dominate industry factors, this factor may proxy for the world market return, ex US.

In Table III, we explore the variation of the interdependence coefficients across portfolios, aggregating over regional groups and different industries. With the exception of Western Europe, the exposures to the domestic factor still dominate the exposures to the US or global financial factors. Emerging markets generally have low exposures to the U.S. and global financial factors with the exception of a relatively high Latin American exposure to the U.S. factor. The variation of the different exposures across different industries is much smaller than across regions. Striking is the low exposure of the technology sector to the global, and its large exposure to the US factor. The highest exposure to the global factor is found for the financial sector, with a beta estimate of 0.58 . In addition, the financial sector has a relatively high exposure vis-à-vis the US factor.

What would the model predict for the crisis? If the model is correctly specified, the factor exposures are sufficient to predict the relative vulnerability across the different portfolios during the crisis. The first columns of Table IV and Figure 1 represent the performance of the "interdependence model" to predict the relative stock return performances across countries. In Figure 1, we graph the actual cumulative returns across the crisis period on the vertical axis against their predicted values from the interdependence model (10) on the horizontal axis. The computation is straightforward. From estimating (10), we obtain $\hat{R}_{i, t}$ for each portfolio $i$ and each week $t$, and then obtain from these the total predicted return $\hat{R}_{i}$ and compare this to the total actual return $R_{i}$ over the crisis period. ${ }^{11}$

\section{Figure 1, Table IV}

If the model predicts the relative crisis severity perfectly, the regression line through the scatter plot should be identical to the 45 degree line. However, it is clear this is not the case. Running a regression of actual on predicted returns for all 415 portfolios, we find:

$$
R_{i}=\underset{(2.444)}{-7.037+0.489 \hat{R}_{i}+\varepsilon_{i}, \operatorname{adj} . R^{2}=0.301}
$$


with the joint test that the intercept is zero and the slope coefficient is unity being rejected. This relationship between actual and predicted returns is graphically shown through the line in Panel A of Figure 1.

Panel B of Figure 1 shows the distribution aggregated across countries, where actual and predicted returns for countries are equally weighted averages across the portfolios of a particular country. On average the model under-predicts the severity of the crisis for nearly all countries and the prediction errors for some countries are quite large. To make the performance of the model more concrete, the first set of columns 1 in Table IV lists the various countries, ranked from worst to best actual crisis performance, then contrasts these returns with the predicted returns based on the threefactor interdependence model in the second set of columns (the table also shows the estimates for the contagion model, to which we turn in the next section).

What is striking from the table is that most of the worst performing countries are in Eastern Europe. This makes sense intuitively as these countries were affected not only the strongest in terms of equity market performance, but also in terms of economic growth and activity. However, the interdependence model would predict some of the Eastern European countries to be only moderately affected. The Spearman rank correlation between actual and predicted returns is a relatively modest 0.68. It would be much smaller if the model did not include a domestic factor. The presence of a domestic factor allows Eastern European countries to be affected by the severe country-specific crises in their countries. Even so, the model still fails to predict the absolute and relative severity of the crisis. Many commentators have expressed surprise about the relatively good performance of many emerging markets, such as Thailand and Indonesia in South-East Asia, or Mexico and Brazil in Latin America, which were at the heart of previous crises. However, from the perspective of our benchmark model, the performance in three of these countries was actually worse than expected (Mexico being an exception).

\section{Table V}

Table $\mathrm{V}$ provides an analogous ranking for each of the 10 sectors, where all returns of portfolios within a particular sector are equally weighted averages across countries. Expected returns and realized returns are much more similar and highly correlated, especially in their ranking (with a Spearman rank correlation of 0.89), thus not exhibiting the same mismatch as across countries. For 
instance, equity returns in utilities, non-cyclical consumer goods or in the energy sector were indeed relatively less affected as predicted by the factor model, and the financial sector was most affected in the data and in the model.

\section{Figure 2}

The three-factor interdependence model fails to fully explain the crisis severity, but the fit shown in Figure 1 still suggests that the interdependence model explains a non-negligible fraction of the cross-sectional variation in crisis returns. To benchmark this model, we compare the predictive power of this model with that of a more standard World CAPM model. We do so by re-estimating (10) including only the two common world factors, the US factor and the global factor. Figure 2 shows the fit of the model, again at the country and at the portfolio levels. A regression of actual on predicted returns for all 415 portfolios for this two-factor model yields:

$$
R_{i}=-13.036+0.256 \hat{R}_{i}+\varepsilon_{i} \text {, adj. } R^{2}=0.094
$$

The $R$-squared decreases from 0.301 in the three-factor model with the domestic factor to only 0.094 for the two-factor model without the domestic factor. Moreover, the slope coefficient of the twofactor model is substantially smaller as it drops by about one half. Overall, this suggests that the domestic factor is indeed highly important in improving the predictive power of the model for the 200709 financial crisis, even without yet allowing for contagion in the model specification.

In summary, the exploratory analysis of this sub-section shows that a simple constant beta model fails to fully explain the transmission of the 2007-09 financial crisis to equity markets globally.

\section{B. Contagion}

\section{B.1. Estimation Results}

Was there contagion in global equity markets during the 2007-09 financial crisis? If so, what type of contagion - did contagion primarily emanate from the global financial sector, from the US or from the domestic market? To address these questions, Table VI reports estimation results of model (1)-(4), but still restricting the coefficients on $Z_{i, t}$ to be zero: 


$$
\begin{aligned}
& R_{i, t}=E_{t-1}\left[R_{i, t}\right]+\beta_{i, t}^{\prime} F_{t}+\eta_{i, 0} C R_{t}+e_{i, t} \\
& \beta_{i, t}=\beta_{i, 0}+\gamma_{i, 0} C R_{t}
\end{aligned}
$$

Compared to Table II, the $R^{2}$ increases by $4 \%$ and all statistics improve, suggesting that the imposition of constant betas across the two periods was a mis-specification. Still the model remains rejected at the $1 \%$ level. The crisis-specific exposures suffice for the model to eliminate within-country residual correlation and the model fails to reject at the $5 \%$ level for that period. The average residual correlation is also negligible and the diagnostic test is now 336 instead of 482.

\section{Table VI}

We report the average $\gamma_{i, 0}, \beta_{i, 0}$, and $\eta_{i, 0}$ coefficients, revealing several interesting patterns. First, the $\eta$ coefficients are, at least on average, small and insignificant. If there is contagion, it must be captured by changing exposures to the factors. Second, the interdependence coefficients have decreased slightly, already suggesting that "dummying out" the crisis period overall leads to decreased comovement between the portfolios before the crisis. Third, there is statistically strong evidence for the presence of contagion from all three sources: from the U.S. market, from the global financial sector, as well as from the domestic market. Finally, and most strikingly, contagion during the 2007-09 crisis seems to have been primarily domestic in nature. The domestic contagion estimate of 0.249 is much larger than the analogous estimates for US contagion of 0.133 and global contagion of 0.056 . It constitutes an economically large $50 \%$ increase of domestic factor betas.

\section{B.2. Heterogeneity}

The evidence on the average contagion and interdependence parameters of Table VI potentially masks a considerable degree of heterogeneity across equity portfolios. Figure 3 documents that such heterogeneity is indeed substantial. Despite positive contagion on average, there are also a number of portfolios that managed to some extent to decouple from global, U.S. or domestic equity market movements. Given the parameter estimates reported before, it is no surprise that the positive mean is visually most apparent for domestic contagion. 
Figure 3,

Table VII

To provide further insights into this heterogeneity, Table VII provides the parameter estimates of Equations (11)-(12) averaged at the regional (Panel A) and sectoral (Panel B) levels. Panel A confirms that domestic contagion dominates US or global contagion, as the estimates for the former are positive, significant and sizeable for all regions. Only in Latin America is US contagion slightly larger than domestic contagion. Domestic contagion is most important in Emerging Europe and the Middle East/Africa, but Emerging Europe shows significant global and US contagion parameters as well. Moreover, the $\eta$ parameter - measuring equity movements during the crisis which are not accounted for by the three factors - is only negative in a statistically significant fashion for Emerging Europe.

As to the sector analysis in Panel B, there are only three sectors that have significant contagion coefficients for the global factor, namely the energy, financial and technology portfolios. The noncyclical consumer goods sector shows a negative coefficient, suggesting some form of decoupling during the crisis, but the economic effect is certainly not large. Most sectors show positive contagion from the US market, with the strongest effects mostly in the production/manufacturing sectors (industrial, energy, basic materials and utilities). Technology shows a negative coefficient, but this sector was ex-ante heavily exposed to the US factor, and thus partially decoupled during the crisis. There is significantly positive and mostly sizeable domestic contagion for portfolios in 9 out of the 10 sectors (the technology sector is the exception), broadly confirming that domestic contagion is not simply driven by the large response of a few portfolios in a few sectors. Finally, the decline in financial sector equities cannot be fully accounted for by the three factors in the model, i.e. $\eta$ is negative and large at -0.217 . Taken together with the regional results, we conclude that the bulk of the contagion effects can be captured by increases in factor exposures with respect to the three factors.

\section{Table VIII}

A final perspective on the nature of contagion we have uncovered is in Table VIII, which reports the cross-sectional correlations between the various contagion and interdependence coefficients across the 415 portfolios. The interdependence coefficients are substantially positively correlated, suggesting a positive association between domestic and international systematic risk. There is also 
significant but mostly more moderate positive correlation across different types of contagion - those portfolios experiencing more domestic contagion were also more exposed to global and US sources of risk during the crisis.

Most striking is the mostly substantial negative correlation between the interdependence and contagion coefficients, indicating that portfolios that were less exposed to the three factors before the crisis experienced the strongest contagion during the crisis. This is true both for international and domestic exposure. Together with the average evidence on strong domestic and weak US or global financial sector contagion, this evidence seems inconsistent with the "globalization hypothesis." Highly globalized portfolios were not particularly hard hit during the crisis and often experienced declines lower than anticipated from their pre-crisis exposures. Instead, the fate of equity portfolios during the crisis became substantially more linked to that of other domestic portfolios.

\section{B.3. Diagnostics}

Going back to Table IV, the contagion model matches quite well the severity of the equity market collapse during the 2007-09 crisis. First, the third set of columns of Table IV shows much less systematic downward bias than the interdependence model, almost perfectly matching the equity market collapse for a number of countries. Second, the contagion model also fits the cross-country differences in severity across countries; in fact, the Spearman rank correlation is 0.91 for the contagion model, substantially higher than the 0.68 rank correlation recorded for the interdependence model.

\section{Figure 4, Table IX}

The goodness of fit of the contagion model is illustrated graphically in Figure 4. Unlike the interdependence model (Figure 1), the predicted overall crisis returns from the contagion model are very similar to the actual overall returns, both at the portfolio level and at the country level. A regression of actual on predicted returns from the contagion model at the portfolio level yields:

$$
R_{i}=1.910+0.971 \hat{R}_{i}+\varepsilon_{i} \text {, adj. } R^{2}=0.843
$$


The slope coefficient is close to unity, and the R-squared is $84 \%$, confirming the good fit. The joint hypothesis that the intercept is zero and the slope coefficient unity is not rejected.

Table IX reports two final diagnostics. Panel A shows the average increase in correlation with the factor returns during the crisis period in the actual data, and compares it to that produced by the interdependence model and the contagion model, respectively. To implement these computations, we computed fitted returns from the interdependence model and from the contagion model, and then calculate correlations for each country-sector portfolio with the returns of a benchmark portfolio (the US market, the global market, and the domestic market - reflecting the three factors in the model), for the pre-crisis and the crisis period separately. These correlations essentially reflect the product of the portfolio's beta with respect to a volatility ratio (factor over portfolio) and thus increases in correlations are produced by increases in this volatility ratio or increases in the betas. We find that correlations with the US and global factors increase by about 0.2 , whereas correlations with the domestic factor increase by about 0.1 . The interdependence model does reasonably well fitting the average increase in correlations with the US and global factors (because volatility ratios increase), but does not generate any increase in correlation with the domestic factor. The contagion model produces realistic increases with respect to all three factors although it still under-predicts the average increase in the correlation with the domestic factor.

Implicitly, these results show that the interdependence model may explain a non-trivial part of the predictable variation in returns during the crisis. This is confirmed more directly by the variance ratio analysis in Panel B of Table IX. For each factor k (US factor, global factor and domestic factor) we calculate the variance ratio for the fitted returns in the contagion model as:

$$
V R_{\beta}^{k}=\frac{\operatorname{cov}\left[\hat{R}_{i, t}, \beta^{k} F_{i, t}^{k}\right]}{\operatorname{var}\left[\hat{R}_{i, t}\right]}
$$

for the interdependence parameters and

$$
V R_{\gamma}^{k}=\frac{\operatorname{cov}\left[\hat{R}_{i, t}, \gamma^{k} F_{i, t}^{k}\right]}{\operatorname{var}\left[\hat{R}_{i, t}\right]}
$$


for the contagion parameters. ${ }^{12}$ By definition, these variance ratios will add to 1 (except for the fact that expected returns also explain a minuscule part of return variation). Panel B of Table IX presents the averages of the variance ratios across portfolios, for each of the factors, during the crisis period. Two points stand out. First, the interdependence model explains $75 \%$ of the movements in returns, and the shift in exposures accommodated in the contagion model, 25\%. Residual contagion, as captured by the $\eta$-coefficients, explains a negligible part of return variation and is not reported. In other words, once we control for the non-linearities in factor returns, a linear model explains a relatively large portion of return variation in the crisis even when factor exposures are kept constant. Second, the main type of contagion that matters is domestic contagion. This again underscores our overall finding that global contagion and US contagion were less important during the crisis, but that domestic contagion was economically important.

\section{B. 4. Robustness and other crises}

As a check of the robustness of the definition of the three factors $F_{t}$, we have also estimated an alternative factor model with the world market return as the global factor, the US financial sector as the US factor and the domestic market return as domestic factor. Such a model delivers qualitatively similar results.

\section{Table X}

Table $\mathrm{X}$ reports a robustness test for the definition of the financial crisis, where the crisis starts only with the collapse of Lehman Brothers in mid-September 2008 (rather than in early August 2007 as in the benchmark). As shown in the second set of columns, this makes no meaningful difference to the findings. In fact, the domestic contagion parameter becomes somewhat larger, while there is little change in the coefficients for US and global contagion. We do observe now a significantly negative $\eta$ coefficient.

An intriguing question is whether the 2007-09 crisis differs with regard to the transmission mechanism and contagion from other past crises. Since our sample starts only in 1995, and going back further would substantially reduce the sample size (in particular with regard to emerging economies), the two equity market collapses we focus on are the 1998 LTCM crisis and the strong decline of equity 
markets between 2000 and 2002 (the TMT bust). Table X shows the estimates for these two events, based on an estimation of the contagion model, but excluding the 2007-09 financial crisis from the sample. The findings indicate that there was little if any contagion during those two episodes. For the LTCM crisis, the global and US contagion parameters are significant and negative, suggesting a slight de-coupling of equity markets with the US market or the global financial sector during those episodes. There appears to be significant residual contagion, the $\eta$-coefficient indicates a statistically significant 18 basis point underperformance during that crisis, not related to any of the factors. For the TMT bust, not a single contagion coefficient is significant at even the $5 \%$ level. This essentially means that an interdependence model would have correctly described the incidence and transmission of the crisis. Importantly, there is no evidence for domestic contagion during either of these early equity market crises. Hence the importance and even dominance of domestic contagion appears to be a truly defining feature of the 2007-09 crisis.

\section{Channels of contagion and interdependence}

The analysis so far has revealed substantial heterogeneity in the contagion and interdependence coefficients across individual country-sector equity portfolios. What explains this heterogeneity? Is it related to the external exposure of portfolios (the "globalization hypothesis") to country-specific factors and risks (the "wake-up call hypothesis"), or to other common factors? We now turn to formally examining the channels of contagion and interdependence.

\section{Table XI}

Table XI reports estimates of the full contagion model (1) - (4) with each instrument $Z_{i, t}$ included individually in the model. This table provides a general idea of potentially important relationships. Of course, many of these instruments, such as banking and external exposures, are highly temporally and cross-sectionally correlated, so it will be important to conduct a multivariate analysis to determine the instruments that really matter.

The banking channel results show that in normal times factor exposures are increasing in international banking links and credit growth. Portfolios with large interest rate exposure are less exposed to the international factors and more exposed to the domestic factor, perhaps because they 
comprise bank-dependent smaller firms. In terms of contagion, large banking exposures to the US and to the rest of the world, as well as high credit growth and financial constraints of domestic firms all raised the intensity of domestic contagion during the crisis. Moreover, higher banking sector exposure generally lowers contagion from the U.S. factor. This increased relative importance of the domestic factor as a function of banking exposure during the crisis appears inconsistent with the globalization hypothesis, but it does not mean banking exposure did not transmit to local markets. It is conceivable that in countries with more international banking exposure, bank financing became particularly difficult, increasing comovements of stocks within the country. There are potential correlations here with other fundamentals and global exposure that must be taken into account and we do so shortly.

We find that government policies to protect the domestic banking sector, such as through debt and deposit guarantees and through capital injections into domestic banks, have reduced contagion during the crisis, and foremost domestic contagion. Thus, government policies have helped de-link the domestic economy, to some extent, from problems in the domestic banking system.

Larger external exposure via trade and financial linkages increases the interdependence coefficients, in particular interdependence with the US and global factors. For instance, trade integration during non-crisis times has, not surprisingly, strong effects on the exposures of the portfolios with respect to global and US factors, confirming results in the literature (see e.g. Baele, 2005). During the crisis, the dependence of the factor loadings on external exposure (through trade integration, capital flows and financial integration) decreased substantially. For example, the overall effect of trade integration on the US, global and domestic factor betas remains positive, as the sum of the (positive) interdependence and (negative) contagion coefficients remains positive, but it is statistically insignificant. In other words, the important message from these estimates is that the globalization hypothesis is strongly rejected by the data as the behavior of portfolios decoupled from their pre-crisis external dependence. The effect is exacerbated by the temporary collapse in trade and capital flows observed during the crisis, which decreased the instrument values as well. Exchange rate exposure decreases betas in normal times, and even more so during the crisis. While the decoupling during the crisis is consistent with our early results, the negative beta dependence on exchange rate exposure in normal times is somewhat puzzling. 
The information asymmetry proxies yield weak results. It is intuitive that "distance” increases domestic factor betas, but not that it increases the dependence on the US and global financial sector factors in normal times. The US and global financial sector betas depend significantly and positively on newspaper imports in normal times, as expected. There are, however, no real significant contagion effects, with the exception that countries further away from the US overall performed worse (negative $\eta$ coefficient). Differences in opinion are not related to contagion of either the global, US or domestic factors. Of course this does not mean that such differences in opinion may not be relevant, but they may just be hard to capture, in particular in a model such as ours, with data covering a very large and heterogeneous cross-section of countries.

For the fundamental variables, the beta dependence is mostly positive (and negative for unemployment) in normal times. This indicates that well-performing countries tend to be more integrated with global capital markets but also show higher comovements within the country. During the crisis, we find evidence in favor of the wake-up call hypothesis as many domestic macroeconomic fundamentals are significant drivers of contagion. A higher current account deficit and lower foreign exchange reserves very significantly increase the exposure to the domestic factor, whereas poor sovereign ratings and low political stability substantially increase the exposure to the US factor. Equally importantly, the budget position of a country mattered for contagion during the 2007-09 crisis, with a weaker budget balance raising both US and domestic contagion. For each variable, at least one of the contagion parameters is highly statistically significant. Increases in the VIX and Ted spread decrease comovements in normal times. This is potentially consistent with evidence in Bekaert et al (2011) finding more "segmentation" in international portfolios in times of heightened risk aversion. It is surprising that the domestic exposures also decrease at such times, which could indicate that the extent of idiosyncratic risk increases. The contagion parameters are all significant as well and of very similar magnitude than the interdependent coefficients, suggesting the dependence on the VIX and Ted spread was minimal during the crisis. It is quite likely that this result reflects an econometric problem given the highly unusual time series behavior of the two series, being highly co-linear with the crisis dummy itself. Both the VIX and the Ted spread show little variation and are at eventually low levels up and till 
the crisis at which time they increase rapidly and show more substantial variation. This makes them look like a stochastic version of the crisis dummy. We do not feel there is a substantive economic result here, and exclude these time series from our subsequent analysis. The significantly $\eta$ coefficients do make economic sense, indicating that at times of high VIX and TED spread levels, markets generally under-performed.

\section{Tables XII - XIII}

Of course, many of the instruments are highly collinear, such that it is impossible to understand from Table XI which of them are ultimately important. Table XII reports the results of the model selection procedure described earlier. Table XIII gauges the economic significance of the various instruments by reporting the change in the interdependence and contagion coefficients that would result when comparing a portfolio with the determinant at its $75^{\text {th }}$ percentile to a portfolio with the determinant at its $25^{\text {th }}$ percentile (i.e. varying the determinant by the interquartile range over the crosssection and time dimensions). For dummy variables (such as the banking policy variables), we report the difference that results when the variable changes from 0 to 1 .

Table XII shows that simultaneous inclusion of instruments renders the coefficient estimates for many instruments statistically insignificant, with only 11 of 25 instruments surviving the selection procedure. None of the asymmetric information proxies survive. Perhaps surprisingly, most of the proxies for the banking and external exposure channels disappear as well. We find that the coefficients are in line with banking or external links increasing US factor exposures in normal times and decoupling from the US factor during the crisis. Again, we confirm that there is no evidence for the globalization hypothesis. Table XIII shows that these effects are mostly economically small, with the exception that financial integration explains a substantial part of the US factor contagion during the crisis.

By contrast, the results of Table XII further strengthen the conclusion that it has been in particular banking policies and the strength of domestic fundamentals that explain contagion during the 2007-09 financial crisis. Not fewer than 5 out of the 6 macro-fundamental variables survive the model selection procedure. In fact, for several proxies in these categories, the size of the coefficients increases 
substantially in the encompassing approach relative to the univariate approach. The economic importance of these channels for explaining contagion in the crisis is substantial. For instance, recall that the (unconditional) average estimate for domestic contagion in Table VI was 0.249. Looking at the interquartile ranges (during the crisis) in Tables XII and XIII indicates that e.g. the introduction of debt guarantees, a good government budget position, or strong political stability would each by itself have eliminated about half of the domestic contagion effect during the crisis. Comparing a "basket case country" with its fundamentals all at the $25 \%$ of the distribution to a country with strong fundamentals at the $75 \%$ of the distribution, the US factor exposure would be 0.31 larger, the global financial sector exposure 0.23 larger, and the domestic factor exposure 0.33 larger. This again underlines that the wake up hypothesis was the main driver of contagion in the recent crisis.

\section{Conclusions}

The 2007-09 financial crisis has been truly remarkable in its severity and global reach. This paper seeks to understand the global transmission channels of the crisis in equity markets, studying the crosssectional heterogeneity of the crisis incidence across 55 equity markets and 10 sectors. A first key result is that from the perspective of a factor model with global and domestic factors, we find evidence of contagion. The comovements of our portfolios cannot be fully explained with the factor model without allowing for shifts in factor exposures. Yet, the model explains $75 \%$ of total return variation. Second, despite its origination in the US, we find weak evidence of contagion from US markets to equity markets globally during the crisis. Instead, there was contagion from domestic equity markets to individual domestic equity portfolios. Third, the financial crisis did not spread indiscriminately across countries and sectors. The exposure to external factors, such as via banking, trade or financial linkages, played no meaningful role for the global equity market transmission of the 2007-09 financial crisis. However, portfolios in countries with weak economic fundamentals, poor sovereign ratings, and high fiscal and current account deficits experienced more contagion, both from US and domestic markets, and were overall more severely affected by the global financial crisis. This provides strong support for the validity of the "wake-up call” hypothesis as a transmission device of the 2007-09 financial crisis. 
Moreover, the presence of policies to protect domestic banks during the crisis, in the form of debt and deposit guarantees, was instrumental in shielding domestic equity portfolios to some extent from the 2007-09 financial crisis.

The irony of this perhaps most global crisis ever is that a market's external exposure played such a small role in determining its equity market performance. Instead, investors focused primarily on country-specific characteristics and punished markets with poor macroeconomic fundamentals, policies and institutions. Our findings support the recent efforts by policymakers and international organizations to better understand macroprudential risks and perhaps institute a closer surveillance of such risks both at a country level and at a global level. 


\section{References}

Adler, M. and B. Dumas, 1984, Exposure to Currency Risk, Definition and Measurement, Financial Management, 13 (2), 41-50.

Adrian, T. and H.S. Shin, 2010, Liquidity and leverage, Journal of Financial Intermediation, 19(3), 418-437.

Albuquerque, R., G. H. Bauer and M. Schneider, 2009, Global private information in international equity markets, Journal of Financial Economics, 94(1), 18-46.

Allen, F. and D. Gale, 2000, Financial contagion, Journal of Political Economy, 108(1), 1-33.

Almeida, H., M. Campello and M. Weisbach, 2004, The cash flow sensitivity of cash, Journal of Finance, Vol. LIX, No. 4, August 2004, 1777-1804.

Almeida, H., M. Campello, B. Laranjeira and S. Weisbenner, 2009, Corporate debt maturity and the real effects of the 2007 credit crisis, NBER working paper, No. 14990.

Ammer, J., C. Vega and J. Wongswan, 2008, Do fundamentals explain the international impact of U.S. interest rates? Evidence at the firm level, International Finance Discussion Papers, 952, Board of Governors of the Federal Reserve System.

Baele, L., 2005, Volatility spillover effects in European equity markets, Journal of Financial and Quantitative Analysis, 40(2), 373-401.

Baele, L. and K. Inghelbrecht, 2009, Time-varying integration and international diversification strategies, Journal of Empirical Finance, 16(3), 368-387.

Baker, M., J. Wurgler and Y. Yuan, 2009, Global, local, and contagious investor sentiment, Federal Reserve Bank of Dallas Globalization and Monetary Policy Institute Working Paper 37.

Barberis, N., A. Shleifer and J. Wurgler, 2005, Comovement, Journal of Financial Economics, 75(2), 283-317.

Bekaert, G., and C.R. Harvey, 1995, Time-varying world market integration, Journal of Finance, 50 (2), 403-444.

Bekaert, G. and C.R. Harvey, 1997, Emerging equity market volatility, Journal of Financial Economics, 43, 29-77.

Bekaert G., C.R. Harvey and A. Ng., 2005, Market integration and contagion, Journal of Business, 78(1), 39-70.

Bekaert G., C.R. Harvey, C. Lundblad and S. Siegel, 2011, What segments equity markets?, Review of Financial Studies, 24, 3841-3890.

Bekaert, G., R. Hodrick and X. Zhang, 2009, International stock return comovements, Journal of Finance, 64(6), 2591-2626.

Bodnar, G.M., B. Dumas and R.D. Marston, 2003, Cross-border valuation, The international cost of equity capital, NBER working paper, No. 10115.

Brennan, M. and H. Cao, 1997, International Portfolio Investment Flows, Journal of Finance, 52(5), 1851-1880.

Broner, F. A., R. G. Gelos, C. M. Reinhart, 2006, When in peril, retrench: Testing the portfolio channel of contagion, Journal of International Economics, 69(1), 203-230.

Boyer, BH., T. Kumagai, and K. Yuan, 2006, How do crises spread? Evidence from accessible and inaccessible stock indices, Journal of Finance, 61(2), 957-1003.

Brooks, R. and M. Del Negro, 2006, Firm-Level Evidence on International Stock Market Comovement, Review of Finance, 10, 69-98.

Brunnermeier, M. \& L.H. Pedersen, 2009. Market liquidity and funding liquidity, Review of Financial Studies, 22(6), 2201-2238.

Calomiris, C., I. Love and M. S. Martinez Peria, 2012, Stock returns' sensitivities to crisis shocks: Evidence from developed and emerging markets, Journal of International Money and Finance, (29)7, 743-765.

Caramazza, F. L. Ricci and R. Salgano 2004, International financial contagion in currency crises, Journal of International Money and Finance, 23, 51-70. 
Carrieri, F., V. Errunza and K. Hogan, 2007, Characterizing world market integration through time, Journal of Financial and Quantitative Analysis, 42(4), 915-940.

Daude, C., and M. Fratzscher, 2008, The pecking order of cross-border investment, Journal of International Economics 74(1), 94-119, January 2008.

Diebold, F. and K. Yilmaz, 2010, Better to give than to receive, predictive directional measurement of volatility spillovers, International Journal of Forecasting, (28)1, 57-66.

Dominguez, K. and L. Tesar, 2001, A re-examination of exchange rate exposure, American Economic Review (Papers and Proceedings), 91(2), 396-399.

Dominguez, K. and L. Tesar, 2006, Exchange rate exposure, Journal of International Economics, 68, 188-218.

Dumas, B., K.Lewis and E. Osambela, 2011, Differences of opinion and international equity markets, NBER Working Paper No. 16726.

Dumas, B. and B. Solnik, 1995, The world price of foreign exchange risk, Journal of Finance, 50, 445479.

Dungey, M., R. Fry, B. Gonzalez-Hermosillo and V.L. Martin, 2004, Empirical modeling of contagion, a review of methodologies, Quantitative Finance, 5(1), 9-24.

Eichengreen, B., A. Mody, M. Nedeljkovic, and L. Sarno, 2009, How the subprime crisis went global, evidence from bank credit default swap spreads, NBER Working Paper, No. 14904.

Engle, R., T. Ito and W.L. Lin, 1990, Meteor showers or heat waves? Heteroskedastic intra-daily volatility in the foreign exchange market, Econometrica, 58(3), 525-542.

Ferson, W., and C. Harvey, 1991, The Variation of Economic Risk Premiums, Journal of Political Economy, 99, 385-415.

Forbes, K, 2004, The Asian flue and Russian virus, the international transmission of crisis in firm-level data, Journal of International Economics, 63, 59-92.

Forbes, K. and R. Rigobon, 2002, No contagion, only interdependence, measuring stock market comovements, Journal of Finance, 57(5), 2223-2261.

Frankel, J. A. and G. Saravelos, 2010, Are Leading Indicators of Financial Crises Useful for Assessing Country Vulnerability? Evidence from the 2008-09 Global Crisis, NBER Working Papers, No. 16047.

Fratzscher, M., 2009, What explains global exchange rate movements during the financial crisis? Journal of International Money and Finance, 28(8), 1390-1407.

Fratzscher, M., 2012, Capital Flows, Push versus Pull Factors and the Global Financial Crisis, forthcoming Journal of International Economics 88(2), November 2012.

Goldstein, M., 1998, The Asian financial crisis causes, cures, and systematic implications, Institute for International Economics, June 1998, Washington D.C.

Goldstein, M., G.L. Kaminsky, and C.M. Reinhart, 2000, Assessing financial vulnerability, Developing an early warning system for emerging markets, Washington D.C., Institute for International Economies.

Hau, H and S. Lai, 2011, The role of equity funds in the financial crisis propagation, Swiss Finance Institute Research Paper, No. 11-35.

Hendry, D.F. and H.M. Krolzig, 2005, The properties of automatic "GETS" modelling, Economic Journal, 115(502), C32-C61, 03.

Kaminsky, G.L., R. Lyons and S. Schmukler, 2004, Managers, Investors, and Crises: Investment Strategies of Mutual Funds, Journal of International Economics 64(1), 113-134.

Kaminsky, G.L. and C.M. Reinhart, 2000, On crises, contagion, and confusion, Journal of International Economics, 51(1), 145-168.

Karolyi, A., 2003, Does international finance contagion really exist? International Finance, 6, 179-199.

King, M.A. and S. Wadhwani, 1990. Transmission of volatility between stock markets, Review of Financial Studies, 3, 5-33.

King, M.R. 2009. Time to buy or just buying time? The market reaction to bank rescue packages BIS working paper No 288. 
Kodres, L.E. and M. Pritsker, 2002, A rational expectations model of financial contagion, Journal of Finance, 57(2),769-799.

Kyle, A.S. and W. Xiong, 2001, Contagion as a wealth effect, Journal of Finance, 56(4), 1401-1440.

Masson, R., 1999, Multiple equilibria, contagion, and the emerging market crises, Proceedings, Federal Reserve Bank of San Francisco, Sept. 1999.

Masulis, R., Y. Hamao and V. Ng, 1990, Correlations in price changes and volatility across international stock markets, Review of Financial Studies, 3(2), 281-308.

Mendoza, Enrique G., Quadrini, Vincenzo, 2010, Financial globalization, financial crisis and contagion, Journal of Monetary Economics, 57(1), 24-39.

Newey, W.K. and K.D. West, 1987, A Simple, Positive Semi-definite, Heteroskedasticity and Autocorrelation Consistent Covariance Matrix, Econometrica, 55(3), 703-08.

Portes, R. and H. Rey, 2005, The determinants of cross-border equity flows, Journal of International Economics, 65(2), 269-296.

Pukthuanthong, K. and R. Roll, 2009, Global market integration: An alternative measure and its application, Journal of Financial Economics, 94(2), 214-232.

Rose, A. and M. Spiegel, 2010, Cross-country causes and consequences of the 2008 crisis, international linkages and American exposure, Pacific Economic Review, 15(3), 340-363.

Rose, A. and M. Spiegel, 2011, Cross-country causes and consequences of the crisis, an update, European Economic Review, 55(3), 309-324.

Stulz, R. and A. Beltratti, 2009, Why did some banks perform better during the credit crisis? A crosscountry study of the impact of governance and regulation, Fisher College of Business Working Paper, 2009-12, Ohio State University.

Tong, H. and S.-J. Wei, 2010, The misfortune of non-financial firms in a financial crisis, disentangling finance and demand shocks, in Wealth, Financial Intermediation and the Real Economy, National Bureau of Economic Research.

Tong, H. and S.-J. Wei, 2011, The composition matters, capital inflows and liquidity crunch during a global economic crisis, Review of Financial Studies, 24(6), 2023-2052.

Van Rijckeghem, C. and B. Weder, 2001, Sources of contagion, is it finance or trade? Journal of International Economics, 54(2), 293-308.

Whited, T. and G. Wu, 2006, Financial constraints risk, Review of Financial Studies, 19(2), 531-559. 


\section{A. All Portfolios}



B. Countries

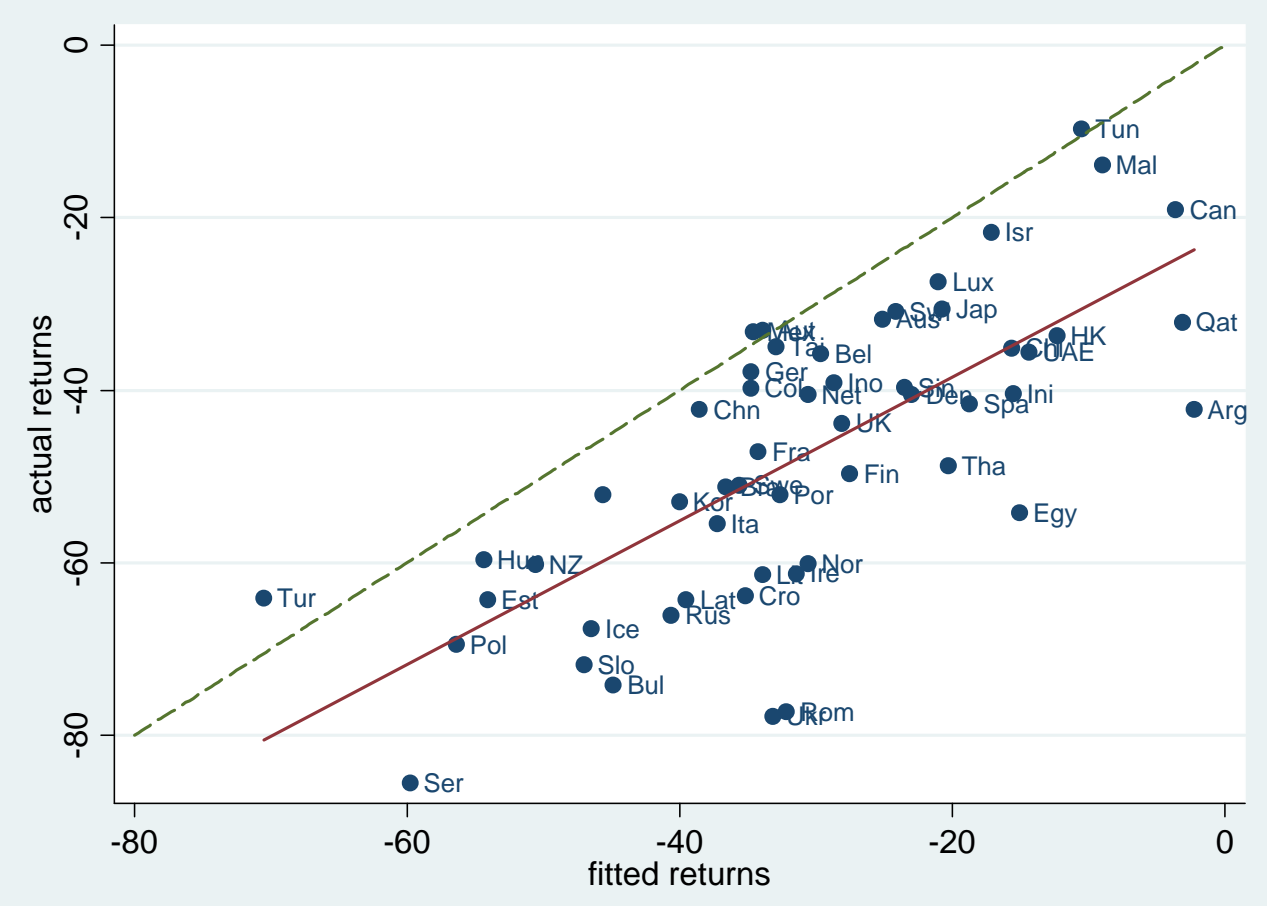

Figure 1: Goodness of fit - Interdependence model. The figures show the total actual equity market returns over the entire crisis period (August 2007 - March 2009) against the fitted total returns from the interdependence model (10), by portfolio (Panel A) and by country (Panel B). Country returns in Panel B are unweighted averages of portfolios within countries. The dashed line shows the 45 degree line. 


\section{A. All Portfolios}

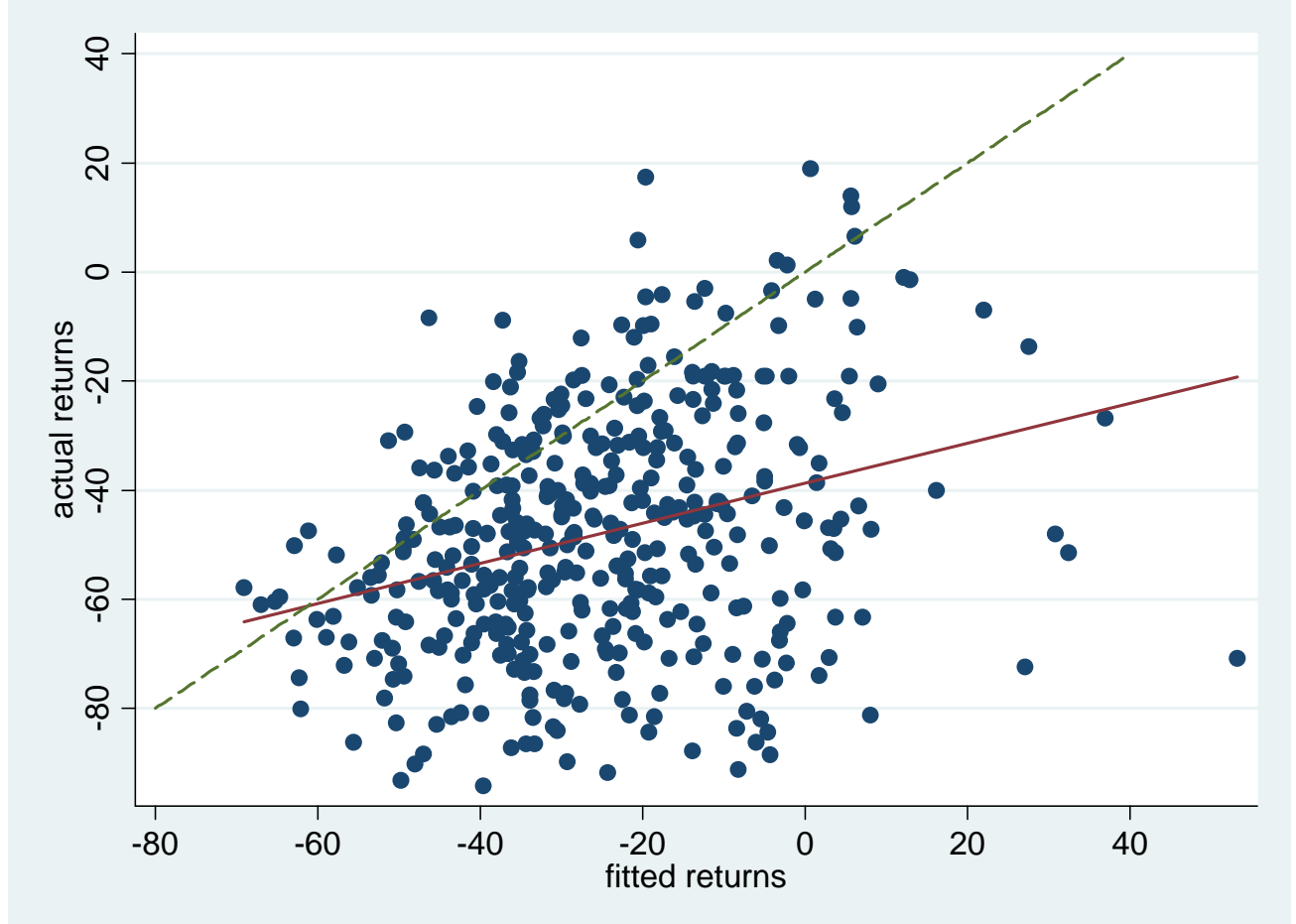

B. Countries

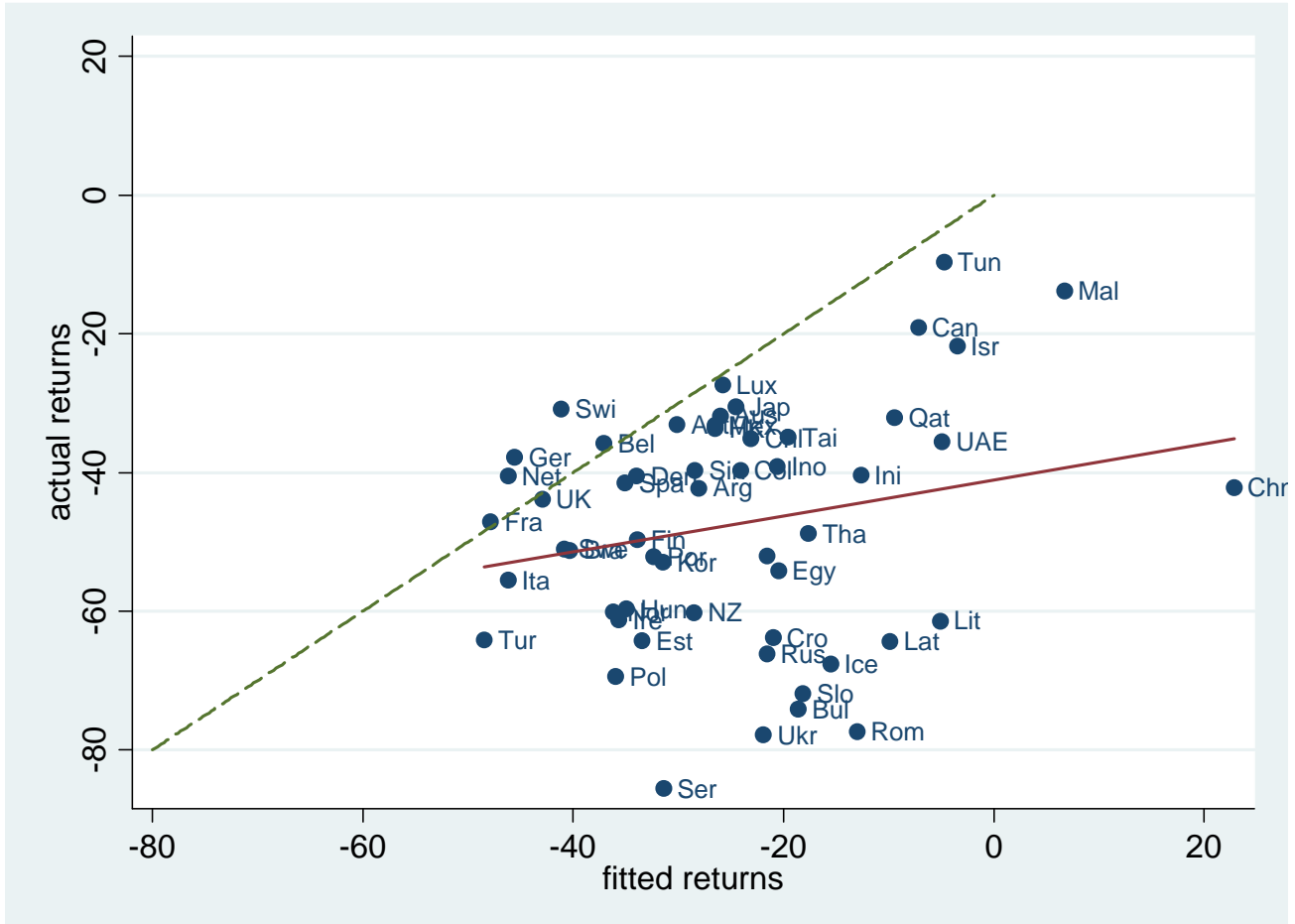

Figure 2: Goodness of fit - Interdependence model - World CAPM (no domestic factor). The figure is based on the two-factor model without the domestic factor (i.e. only the global and US factors). It shows the cumulated actual equity market returns over the entire crisis period (August 2007 - March 2009) against the fitted cumulated returns from the interdependence model, by portfolio (Panel A) and by country (Panel B). Country returns in Panel B are unweighted averages of portfolios within countries. The dashed line shows the 45 degree line. 
A. Contagion from US market

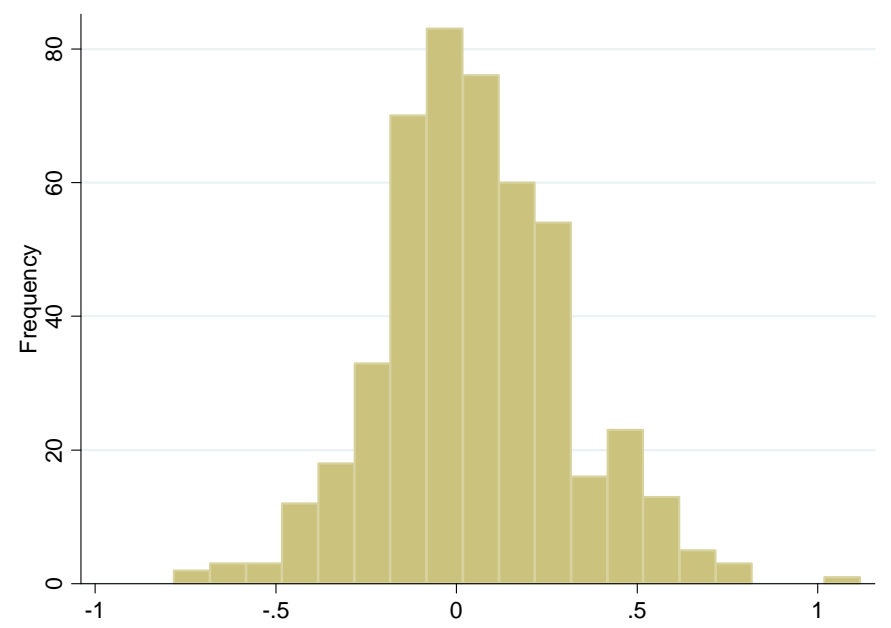

B. Contagion from the global financial sector

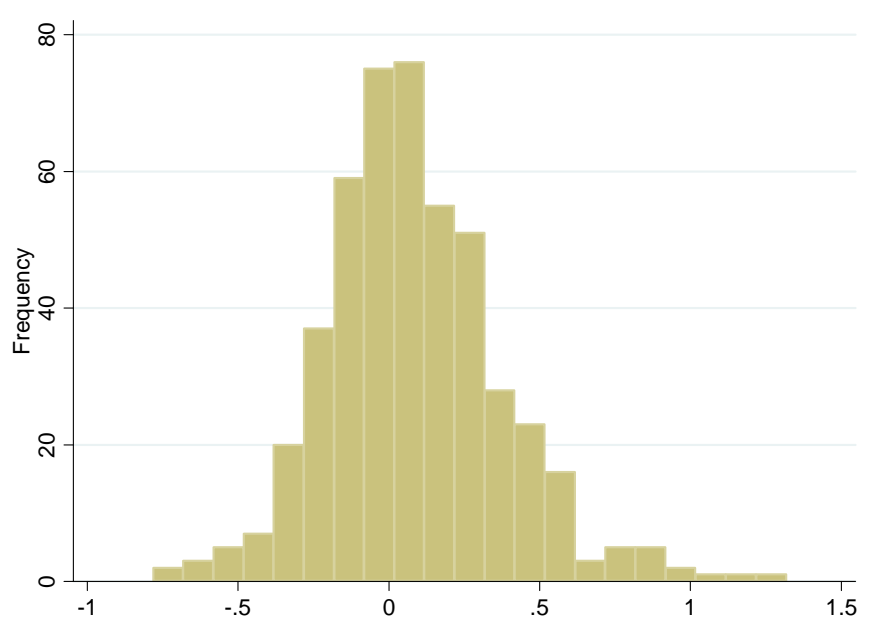

C. Contagion from domestic market

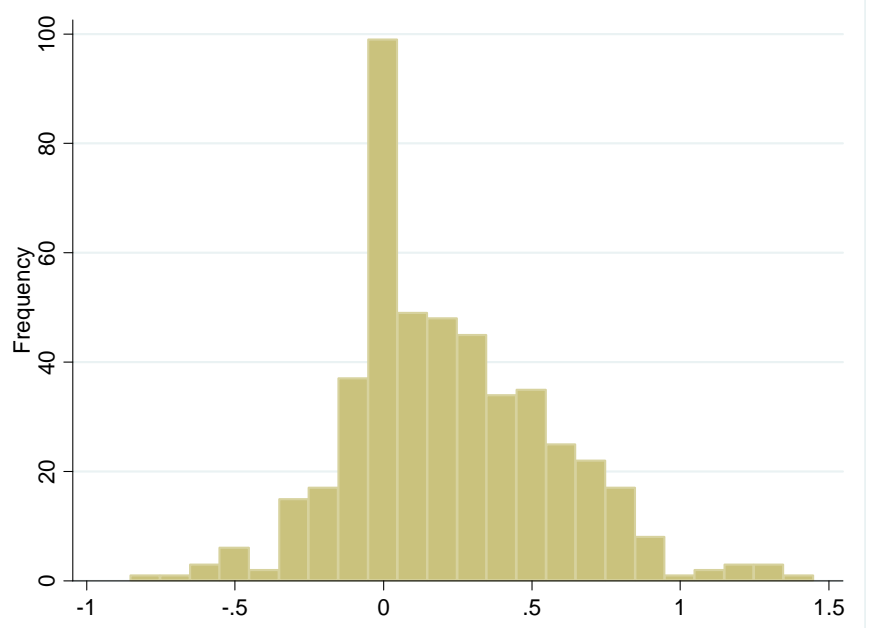

Figure 3: Distribution of Contagion Coefficients. The figures show the distribution of the contagion coefficients $\gamma_{t, 0}$ from the estimation of (11)-(12) across all 415 equity portfolios from the factor model. 


\section{A. All Portfolios}

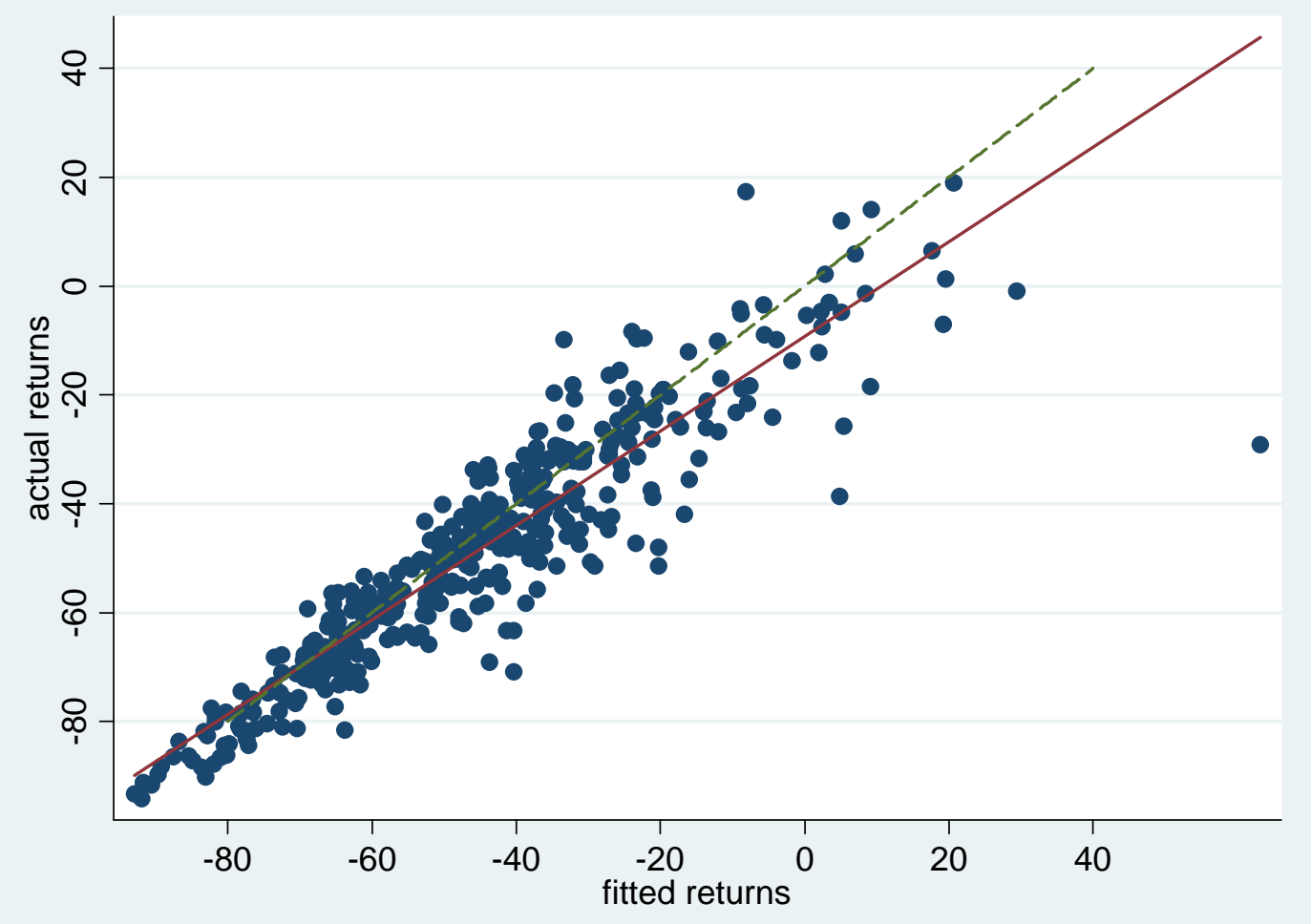

B. Countries

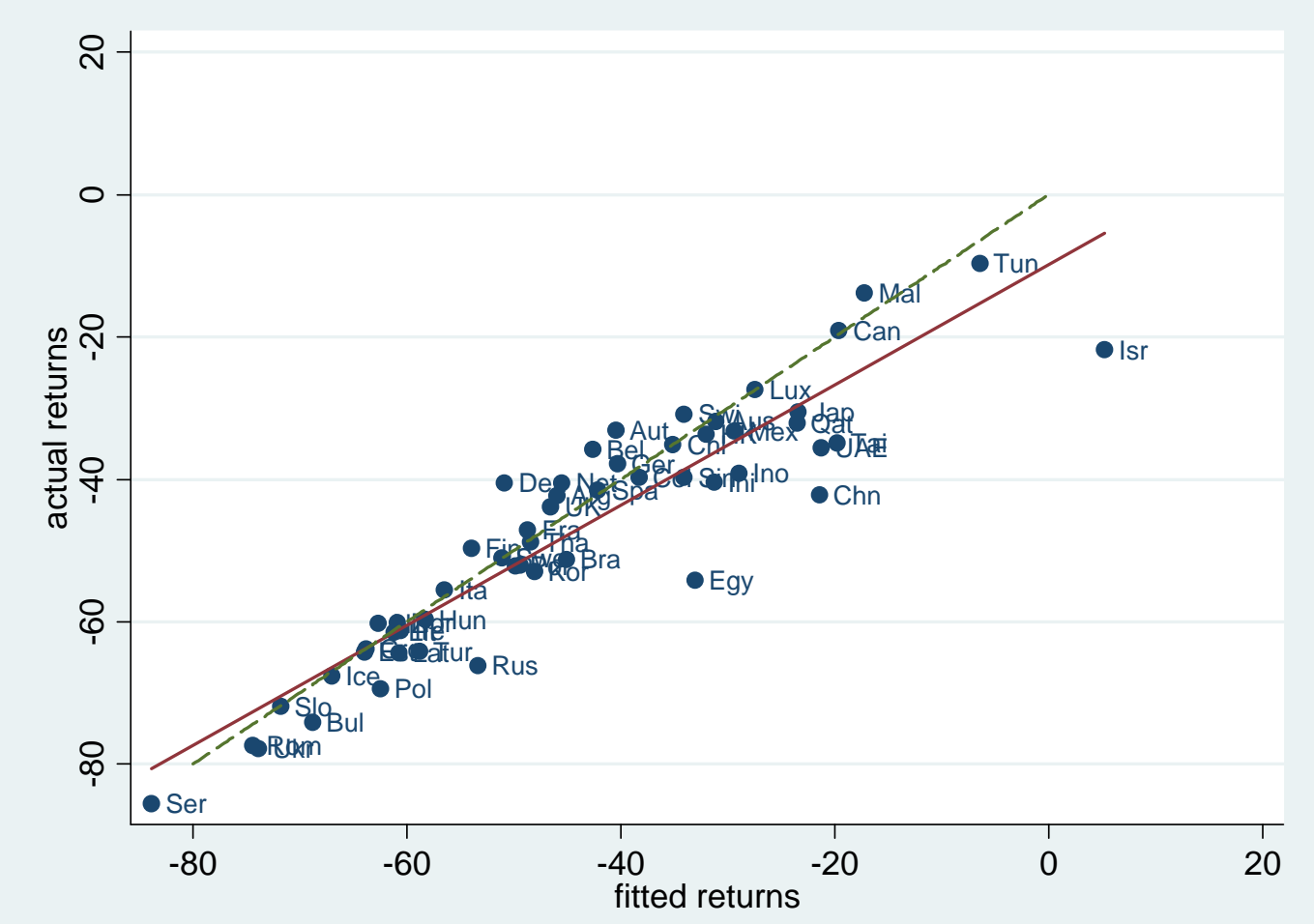

Figure 4: Goodness of fit -Contagion model. The figures show the cumulated actual equity market returns over the entire crisis period (August 2007 - March 2009) against the fitted cumulated returns from the contagion model (11) and (12), by portfolio (Panel A) and by country (Panel B). Country returns in Panel B are unweighted averages of portfolios within countries. The dashed line shows the 45 degree line. 
Table I: Factor Exposure Instruments

The summary statistics shown in the table are calculated across the $\mathbf{4 1 5}$ portfolios for the entire sample period.

\begin{tabular}{|c|c|c|c|c|c|c|c|c|c|}
\hline Variables & Units & Frequency & Definition & Unit of observation & Source & mean & s.d. & $\min$. & max. \\
\hline \multicolumn{10}{|l|}{ Banking exposure } \\
\hline Banking exposures to the US & $\%$ of GDP & Annual & $\begin{array}{l}\text { Foreign claims (assets incl. deposits, loans, debt securities) of domestic } \\
\text { banks vis-a--vis US banks, scaled by GDP }\end{array}$ & Country & BIS Consolidated statistics & 1.71 & 1.11 & 0.01 & 11.81 \\
\hline $\begin{array}{l}\text { Banking exposures to the rest } \\
\text { of the world }\end{array}$ & $\%$ of GDP & Annual & $\begin{array}{l}\text { Foreign claims (assets incl. deposits, loans, debt securities) of domestic } \\
\text { banks vis-a--vis rest-of-the-world banks, scaled by GDP }\end{array}$ & Country & BIS Consolidated statistics & 16.36 & 11.68 & 0.12 & 90.49 \\
\hline Credit growth & in $\%$ & Constant & Annual growth rate of credit to private sector (av. 2003-07) & Country & IMF, Haver, Bloomberg & 15.41 & 15.82 & -55.70 & 98.80 \\
\hline Interest rate exposure & $\%$ of GDP & Constant & Estimated exposure coefficient, see Appendix B & Country - Sector & IMF, Bloomberg, authors' estimates & 3.99 & 126.88 & -833.5 & 577.24 \\
\hline Size & $\log$ USD values & Quarterly & Total assets & Country - Sector & Bloomberg & 9.42 & 3.11 & 0.68 & 18.10 \\
\hline Financial constraints & index from 0-100 & Quarterly & Estimate based on Whited and Wu (2006), see Appendix B & Country - Sector & Bloomberg, authors' estimates & 60.83 & 43.22 & 0.09 & 99.57 \\
\hline \multicolumn{10}{|l|}{ Banking policy } \\
\hline Debt guarantees & 0-1 dummy & Weekly & Dummy $=1$ after announcement of policy measure & Country & BIS, CGFS database, Bloomberg & 0.32 & 0.47 & 0 & 1 \\
\hline Deposit guarantees & $0-1$ dummy & Weekly & Dummy=1 after announcement of policy measure & Country & BIS, CGFS database, Bloomberg & 0.44 & 0.50 & 0 & 1 \\
\hline Capital injections & 0-1 dummy & Weekly & Dummy=1 after announcement of policy measure & Country & BIS, CGFS database, Bloomberg & 0.26 & 0.44 & 0 & 1 \\
\hline \multicolumn{10}{|c|}{ External exposure/segmentation } \\
\hline Capital flows & $\%$ of GDP & Monthly & $\begin{array}{l}\text { Net sales of long-term US securities by domestic residents and of foreign } \\
\text { securities to US residents, scaled by country GDP; a positive number } \\
\text { means a net inflow of capital into country } X \text { from the US }\end{array}$ & Country & $\begin{array}{l}\text { US Treasury International Capital (TIC) } \\
\text { data }\end{array}$ & -1.19 & 9.87 & -24.42 & 64.41 \\
\hline Financial integration & $\%$ of GDP & Annual & Stock of portfolio assets \& liabilities with the US, scaled by GDP & Country & IMF, CPIS data & 36.75 & 67.61 & 0.07 & 778.01 \\
\hline Financial depth & $\%$ of GDP & Quarterly & Equity market capitalization, scaled by GDP & Country & Bloomberg & 71.86 & 90.59 & 4.60 & 593.90 \\
\hline Trade integration & $\%$ of GDP & Annual & Sum of exports and imports with the US, scaled by GDP & Country & IMF, Haver, Bloomberg & 108.39 & 76.43 & 28.17 & 455.40 \\
\hline Exchange rate exposure & $\%$ of GDP & Constant & Estimated exposure coefficient, see Appendix B & Country - Sector & IMF, Bloomberg, authors' estimates & -8.42 & 93.56 & -690.8 & 808.82 \\
\hline Difference in opinion & $\begin{array}{l}\text { correlation between }-1 \\
\text { and }+1\end{array}$ & & $\begin{array}{l}\text { Correlation of (a) bilateral capital flows from the US to destination country } \\
\text { (as defined above) and (b) destination country's local equity returns before } \\
\text { the crisis (in 2006) }\end{array}$ & Country & $\begin{array}{l}\text { US Treasury International Capital (TIC) } \\
\text { data, Bloomberg }\end{array}$ & 0.20 & 0.17 & -0.17 & 0.76 \\
\hline \multicolumn{10}{|l|}{ Information asymmetries } \\
\hline Distance & in $\mathrm{km}$, logs & Constant & Log distance between country $X$ 's capital city and the US & Country & $\begin{array}{l}\text { A. Rose website, Daude-Fratzscher } \\
\text { (2008) }\end{array}$ & 8.56 & 0.39 & 6.98 & 9.15 \\
\hline Telephone traffic & in 1000 & Constant & Volume of telephone calls traffic with the US (av. 2003-7) & Country & ITU Directions of Trade & 555 & 1178 & 0.00 & 7068 \\
\hline Newspaper imports & in USD million & Constant & Net imports of newspapers and periodicals from US (av. 2003-07) & Country & $\begin{array}{l}\text { UN Comtrade database, Exports of item } \\
8922 \text { SITC Rev.2 }\end{array}$ & 13.15 & 4.08 & -2.16 & 20.15 \\
\hline \multicolumn{10}{|c|}{ Domestic macroeconomic fundamentals } \\
\hline Political stability/institutions & index from 0-50 & Constant & $\begin{array}{l}\text { Political risk index; higher number }=\text { less risk } / \text { better institutions (av. 2003- } \\
\text { 07) }\end{array}$ & - Country & $\begin{array}{l}\text { International Country Risk Guide } \\
\text { (ICRG) }\end{array}$ & 12.89 & 4.39 & 1 & 28 \\
\hline Sovereign rating & $\begin{array}{l}\text { continuous variable, } 6- \\
22\end{array}$ & - Weekly & $\begin{array}{l}\text { Rating of sovereign debt, linear transformation (from highest rating } \\
\text { AAA }=22 \text { decreasing) }\end{array}$ & Country & Bloomberg & 16.29 & 4.75 & 6 & 22 \\
\hline FX reserves & $\%$ of GDP & Annual & Foreign exchange reserves, scaled by GDP & Country & IMF WEO & 18.35 & 4.69 & 4.80 & 100.70 \\
\hline Current account & $\%$ of GDP & Annual & Current account balance, scaled by GDP & Country & IMF WEO & 0.68 & 7.59 & -17.11 & 27.98 \\
\hline Unemployment rate & in \% & Annual & Unemployment rate & Country & IMF WEO & 7.81 & 6.18 & 2.10 & 38.71 \\
\hline Government budget & $\%$ of GDP & Annual & Fiscal balance, scaled by GDP & Country & IMF WEO & -0.18 & 4.24 & -7.80 & 19.61 \\
\hline \multicolumn{10}{|c|}{ Globalcommon risk and liquidity } \\
\hline Risk - VIX & in basis points & Weekly & VIX index based on S\&P500 call options & Global & Bloomberg & 22.00 & 8.92 & 9.89 & 80.86 \\
\hline Credit risk - TED spread & in basis points & Weekly & US TED spread & Global & Bloomberg & 52.18 & 44.97 & 0.11 & 463.08 \\
\hline
\end{tabular}




\section{Table II: Interdependence}

The table shows the estimates of the following model:

$$
R_{i, t}=E_{t-1}\left[R_{i, t}\right]+\beta_{i, 0}{ }^{\prime} F_{t}+e_{i, t}
$$

The table reports the unweighted average degree of interdependence across all portfolios in the sample, where $G$ denotes the global factor, $U$ the US factor, and $D$ the domestic factor. The test statistics are described in section I.B. The critical value of a $\chi^{2}(1)$-distributed variable is $3.84(6.63)$ at the $5 \%(1 \%)$ level. ***, **, and * indicate statistical significance at the $1 \%, 5 \%$, and $10 \%$ levels, respectively.

\begin{tabular}{lc}
\hline & \multicolumn{2}{c}{ Benchmark } \\
& coef $\quad$ st.err. \\
\hline $\begin{array}{c}\text { Interdependence } \\
\beta^{U}\end{array}$ & \\
$\beta^{G}$ & $0.437^{* * *} 0.015$ \\
$\beta^{D}$ & $0.406^{* * *} 0.012$ \\
& $0.540^{* * *} 0.013$ \\
\hline Test statistics & \\
Full Sample & \\
ECTEST & \\
EXCOR & 53.35 \\
ECDIAG & 0.11 \\
Crisis Period & 618.31 \\
ECTEST & \\
EXCOR & 12.09 \\
ECDIAG & 0.11 \\
Observations & 481.56 \\
R-squared & 322216 \\
\hline
\end{tabular}




\section{Table III: Interdependence across Regions and Sectors}

The table shows the estimates of the following model:

$$
R_{i, t}=E_{t-1}\left[R_{i, t}\right]+\beta_{i, 0}{ }^{\prime} F_{t}+e_{i, t}
$$

The table provides estimates of the average degrees of interdependence across portfolios within a particular region (Panel A), and those within a particular sector (Panel B), where $G$ denotes the global factor, $U$ the US factor, and $D$ the domestic factor. ${ }^{* * *}, * *$, and $*$ indicate statistical significance at the $1 \%, 5 \%$, and $10 \%$ levels, respectively.

\section{A. By region}

\begin{tabular}{|c|c|c|c|}
\hline \multirow[b]{2}{*}{ Region } & \multicolumn{3}{|c|}{ Interdependence } \\
\hline & $\beta^{U}$ & $\beta^{G}$ & $\beta^{D}$ \\
\hline Latin America & $0.594 * \star \star$ & $0.360 * \star *$ & $0.604 * \star *$ \\
\hline Western Europe & $0.633 * \star \star$ & $0.539 * \star \star$ & $0.512 * \star \star *$ \\
\hline Emerging Europe & $0.273 * \star \star$ & $0.347^{\star * \star}$ & $0.473 * \star \star$ \\
\hline Middle East/Africa & $0.084 * * *$ & $0.163 * \star \star$ & $0.467 * \star \star$ \\
\hline Developed Asia & $0.494 * * *$ & $0.531 * \star \star$ & $0.655 * * *$ \\
\hline Emerging Asia & $0.267 * * \star$ & $0.350 * \star *$ & $0.679 * \star \star$ \\
\hline
\end{tabular}

\section{B. By sector}

\begin{tabular}{|c|c|c|c|}
\hline \multirow[b]{2}{*}{ Sector } & \multicolumn{3}{|c|}{ Interdependence } \\
\hline & $\beta^{U}$ & $\beta^{G}$ & $\beta^{D}$ \\
\hline Basic Materials & $0.460 * \star \star$ & $0.446 * \star \star$ & $0.586 * \star \star$ \\
\hline Communications & $0.448 * \star \star$ & $0.303 * \star \star$ & $0.562 * \star \star$ \\
\hline Consumer, Cyclical & $0.416 * * \star$ & $0.410 * \star *$ & $0.568 * \star \star$ \\
\hline Consumer, Non-cycl & $0.360 * * *$ & $0.358 * \star \star$ & $0.492 * \star \star$ \\
\hline Diversified & $0.522 * \star \star$ & $0.471 * * \star$ & $0.762 * \star *$ \\
\hline Energy & $0.393 * \star \star$ & $0.402 * * \star$ & $0.499 * * \star$ \\
\hline Financial & $0.492 * \star *$ & $0.583 * * \star$ & $0.476 * \star \star$ \\
\hline Industrial & $0.440 * \star \star$ & $0.421 * \star \star$ & $0.561 * \star \star$ \\
\hline Technology & $0.679 * \star \star$ & $0.249 * \star \star$ & $0.575 * \star \star$ \\
\hline Utilities & $0.291 * \star \star$ & $0.336 * \star \star$ & $0.448 * \star *$ \\
\hline
\end{tabular}


Table IV: Predicting Crisis Returns

The table shows total actual equity market returns over the entire crisis period (Aug. 2007 - March 2009) against the fitted total returns from the interdependence model (see Table II for explanations) and against the fitted total returns from the contagion model (see Table VI). Portfolio returns in the table are averaged within countries. Countries are ranked according to actual equity market returns during the crisis. The model parameters shown are from the contagion model.

\begin{tabular}{|c|c|c|c|c|c|c|c|c|c|c|c|c|c|}
\hline \multirow[b]{3}{*}{ Country } & \multirow{2}{*}{\multicolumn{2}{|c|}{ Actual returns }} & \multirow{2}{*}{\multicolumn{2}{|c|}{$\begin{array}{l}\text { Interdepend. } \\
\text { Model } \\
\text { Fitted returns }\end{array}$}} & \multirow{2}{*}{\multicolumn{2}{|c|}{$\begin{array}{l}\text { Contagion } \\
\text { Model } \\
\text { Fitted returns }\end{array}$}} & \multirow[b]{3}{*}{$\beta^{U}$} & \multirow[b]{3}{*}{$\beta^{G}$} & \multirow{2}{*}{\multicolumn{3}{|c|}{$\begin{array}{l}\text { Model parameters } \\
\text { (contagion model) }\end{array}$}} & \multirow[b]{3}{*}{$\gamma^{D}$} & \multirow[b]{3}{*}{$\eta$} \\
\hline & & & & & & & & & & & & & \\
\hline & returns & rank & returns & rank & returns & rank & & & $\beta^{D}$ & $\gamma^{U}$ & $\gamma^{G}$ & & \\
\hline Serbia & -85.6 & 1 & -59.8 & 2 & -83.9 & 1 & 0.080 & 0.148 & 0.632 & 0.210 & -0.097 & 0.005 & -0.777 \\
\hline Ukraine & -77.9 & 2 & -33.2 & 25 & -73.8 & 3 & 0.180 & 0.217 & 0.227 & 0.074 & 0.178 & 0.612 & -0.496 \\
\hline Romania & -77.3 & 3 & -32.2 & 28 & -74.4 & 2 & 0.231 & 0.287 & 0.302 & 0.119 & 0.032 & 0.410 & -0.878 \\
\hline Bulgaria & -74.2 & 4 & -44.9 & 10 & -68.8 & 5 & 0.029 & 0.245 & 0.191 & 0.271 & 0.195 & 0.541 & -0.075 \\
\hline Slovenia & -71.9 & 5 & -47.0 & 7 & -71.8 & 4 & 0.111 & 0.315 & 0.726 & 0.067 & -0.051 & 0.102 & -0.364 \\
\hline Poland & -69.5 & 6 & -56.4 & 3 & -62.5 & 10 & 0.598 & 0.555 & 0.587 & 0.215 & 0.159 & 0.258 & -0.150 \\
\hline Iceland & -67.7 & 7 & -46.5 & 8 & -67.0 & 6 & 0.174 & 0.325 & 0.472 & 0.014 & -0.126 & 0.014 & -0.396 \\
\hline Russia & -66.2 & 8 & -40.6 & 11 & -53.3 & 19 & 0.304 & 0.186 & 0.291 & 0.239 & 0.328 & 0.355 & -0.076 \\
\hline Latvia & -64.3 & 9 & -39.5 & 13 & -60.7 & 13 & 0.098 & 0.233 & 0.344 & 0.099 & 0.044 & 0.125 & -0.508 \\
\hline Estonia & -64.3 & 10 & -54.1 & 5 & -63.9 & 7 & 0.254 & 0.383 & 0.380 & 0.200 & 0.027 & 0.424 & -0.199 \\
\hline Turkey & -64.1 & 11 & -70.5 & 1 & -58.8 & 15 & 0.721 & 0.662 & 0.824 & 0.039 & 0.372 & 0.017 & 0.083 \\
\hline Croatia & -63.9 & 12 & -35.2 & 18 & -63.8 & 8 & 0.100 & 0.280 & 0.322 & 0.245 & -0.003 & 0.502 & -0.034 \\
\hline Lithuania & -61.4 & 13 & -33.9 & 23 & -61.2 & 11 & 0.129 & 0.266 & 0.407 & -0.001 & 0.019 & 0.310 & -0.356 \\
\hline Ireland & -61.3 & 14 & -31.4 & 29 & -60.6 & 14 & 0.439 & 0.559 & 0.357 & 0.122 & -0.169 & 0.035 & -0.659 \\
\hline New Zealand & -60.2 & 15 & -50.6 & 6 & -62.6 & 9 & 0.362 & 0.326 & 0.641 & 0.168 & 0.124 & 0.164 & -0.345 \\
\hline Norway & -60.1 & 16 & -30.6 & 31 & -60.9 & 12 & 0.487 & 0.454 & 0.620 & 0.330 & 0.021 & 0.127 & -0.311 \\
\hline Hungary & -59.6 & 17 & -54.4 & 4 & -58.3 & 16 & 0.584 & 0.560 & 0.638 & 0.106 & -0.062 & 0.147 & 0.056 \\
\hline Italy & -55.5 & 18 & -37.2 & 15 & -56.4 & 17 & 0.760 & 0.485 & 0.626 & 0.086 & 0.083 & 0.156 & -0.137 \\
\hline Egypt & -54.2 & 19 & -15.1 & 47 & -33.1 & 39 & 0.085 & 0.164 & 0.372 & -0.168 & 0.258 & 0.484 & 0.257 \\
\hline Korea & -52.9 & 20 & -40.0 & 12 & -48.1 & 26 & 0.610 & 0.510 & 0.610 & 0.199 & 0.042 & 0.213 & -0.007 \\
\hline Portugal & -52.1 & 21 & -32.6 & 27 & -49.8 & 22 & 0.388 & 0.459 & 0.610 & 0.132 & 0.013 & 0.182 & -0.092 \\
\hline Czech Republic & -52.1 & 22 & -45.7 & 9 & -49.4 & 23 & 0.291 & 0.557 & 0.534 & 0.129 & 0.017 & 0.136 & -0.094 \\
\hline Brazil & -51.2 & 23 & -36.6 & 16 & -45.1 & 30 & 0.948 & 0.463 & 0.686 & 0.297 & 0.032 & 0.092 & -0.153 \\
\hline Sweden & -51.0 & 24 & -35.6 & 17 & -51.1 & 20 & 0.781 & 0.669 & 0.385 & 0.245 & -0.122 & 0.437 & -0.052 \\
\hline Finland & -49.7 & 25 & -27.5 & 35 & -54.0 & 18 & 0.593 & 0.534 & 0.380 & 0.260 & -0.143 & 0.439 & -0.161 \\
\hline Thailand & -48.8 & 26 & -20.3 & 42 & -48.4 & 25 & 0.306 & 0.420 & 0.530 & 0.129 & 0.148 & 0.241 & -0.400 \\
\hline France & -47.1 & 27 & -34.2 & 22 & -48.7 & 24 & 0.872 & 0.736 & 0.532 & 0.139 & -0.152 & 0.331 & -0.003 \\
\hline UK & -43.9 & 28 & -28.1 & 34 & -46.5 & 27 & 0.669 & 0.595 & 0.543 & 0.125 & -0.022 & 0.342 & 0.010 \\
\hline Argentina & -42.2 & 29 & -2.2 & 54 & -46.0 & 28 & 0.394 & 0.245 & 0.436 & 0.133 & 0.189 & 0.208 & -0.273 \\
\hline China & -42.2 & 30 & -38.5 & 14 & -21.4 & 48 & -0.012 & 0.087 & 0.701 & -0.279 & 0.002 & 0.125 & 0.050 \\
\hline Spain & -41.6 & 31 & -18.7 & 43 & -42.1 & 32 & 0.646 & 0.568 & 0.542 & 0.152 & 0.017 & 0.301 & -0.060 \\
\hline Netherlands & -40.5 & 32 & -30.6 & 30 & -45.5 & 29 & 0.959 & 0.515 & 0.427 & -0.030 & 0.047 & 0.231 & 0.124 \\
\hline Denmark & -40.5 & 33 & -22.9 & 39 & -50.9 & 21 & 0.511 & 0.673 & 0.307 & 0.181 & -0.044 & 0.380 & -0.119 \\
\hline India & -40.4 & 34 & -15.5 & 46 & -31.3 & 41 & 0.442 & 0.295 & 0.630 & -0.031 & 0.192 & 0.262 & -0.097 \\
\hline Colombia & -39.8 & 35 & -34.8 & 19 & -38.3 & 35 & 0.358 & 0.241 & 0.618 & 0.190 & 0.129 & 0.227 & 0.439 \\
\hline Singapore & -39.7 & 36 & -23.5 & 38 & -34.1 & 37 & 0.560 & 0.602 & 0.570 & 0.058 & -0.153 & 0.313 & 0.008 \\
\hline Indonesia & -39.2 & 37 & -28.7 & 33 & -28.9 & 44 & 0.429 & 0.704 & 0.716 & -0.082 & -0.066 & 0.176 & 0.038 \\
\hline Germany & -37.8 & 38 & -34.7 & 20 & -40.3 & 34 & 1.006 & 0.733 & 0.601 & -0.143 & -0.177 & 0.115 & 0.042 \\
\hline Belgium & -35.7 & 39 & -29.6 & 32 & -42.6 & 31 & 0.495 & 0.581 & 0.512 & 0.149 & -0.028 & -0.033 & 0.000 \\
\hline UAE & -35.6 & 40 & -14.4 & 48 & -21.3 & 49 & 0.002 & -0.027 & 0.143 & -0.177 & 0.214 & 0.422 & 0.441 \\
\hline Chile & -35.1 & 41 & -15.6 & 45 & -35.1 & 36 & 0.501 & 0.282 & 0.680 & 0.130 & 0.035 & 0.256 & -0.130 \\
\hline Taiwan & -34.9 & 42 & -32.9 & 26 & -19.8 & 50 & 0.334 & 0.388 & 0.686 & 0.143 & -0.053 & 0.116 & 0.120 \\
\hline Hong Kong & -33.7 & 43 & -12.3 & 49 & -32.0 & 40 & 0.565 & 0.530 & 0.546 & 0.172 & 0.131 & 0.382 & -0.233 \\
\hline Mexico & -33.2 & 44 & -34.6 & 21 & -29.4 & 43 & 0.785 & 0.361 & 0.591 & 0.058 & -0.014 & 0.105 & 0.054 \\
\hline Austria & -33.1 & 45 & -33.9 & 24 & -40.4 & 33 & 0.478 & 0.596 & 0.638 & 0.119 & 0.001 & 0.077 & 0.244 \\
\hline Qatar & -32.1 & 46 & -3.1 & 53 & -23.5 & 46 & -0.029 & 0.044 & 0.352 & -0.030 & 0.012 & 0.362 & 0.145 \\
\hline Australia & -31.8 & 47 & -25.1 & 36 & -31.1 & 42 & 0.455 & 0.462 & 0.624 & 0.124 & -0.058 & -0.005 & 0.069 \\
\hline Switzerland & -30.8 & 48 & -24.1 & 37 & -34.1 & 38 & 0.775 & 0.682 & 0.532 & 0.016 & -0.059 & -0.087 & 0.146 \\
\hline Japan & -30.6 & 49 & -20.7 & 41 & -23.4 & 47 & 0.296 & 0.567 & 0.771 & 0.058 & -0.004 & 0.036 & 0.041 \\
\hline Luxembourg & -27.4 & 50 & -21.0 & 40 & -27.4 & 45 & 0.276 & 0.509 & 0.152 & 0.199 & 0.002 & 0.324 & 0.268 \\
\hline Israel & -21.7 & 51 & -17.1 & 44 & 5.3 & 54 & 0.363 & 0.217 & 0.584 & 0.052 & -0.067 & 0.282 & 0.106 \\
\hline Canada & -19.1 & 52 & -3.6 & 52 & -19.6 & 51 & 0.221 & 0.127 & 0.206 & -0.030 & 0.013 & 0.145 & -0.140 \\
\hline Malta & -13.8 & 53 & -9.0 & 51 & -17.2 & 52 & 0.002 & -0.141 & 0.324 & -0.035 & 0.029 & 0.179 & 0.056 \\
\hline Tunisia & -9.7 & 54 & -10.5 & 50 & -6.4 & 53 & 0.069 & 0.314 & 0.554 & 0.006 & -0.051 & 0.083 & -0.111 \\
\hline
\end{tabular}




\section{Table V: Predicting Crisis Returns - Distribution at the Sector Level}

The table shows at the sector level the total actual equity market returns over the entire crisis period (August 2007 March 2009) against the fitted total returns from the interdependence model (see Table II for explanations) and against the fitted total returns from the contagion model (see Table VI). Portfolio returns in the table are unweighted averages within sectors. Sectors are ranked according to actual equity market returns during the crisis. The model parameters are from the contagion model specification (see Table VI).

\begin{tabular}{|c|c|c|c|c|c|c|c|c|c|c|c|c|c|}
\hline \multirow[b]{3}{*}{ Sector } & \multirow{2}{*}{\multicolumn{2}{|c|}{ Actual returns }} & \multirow{2}{*}{\multicolumn{2}{|c|}{$\begin{array}{l}\text { Interdepend. } \\
\text { Model } \\
\text { Fitted returns }\end{array}$}} & \multirow{2}{*}{\multicolumn{2}{|c|}{$\begin{array}{l}\text { Contagion } \\
\text { Model } \\
\text { Fitted returns }\end{array}$}} & \multirow[b]{3}{*}{$\beta^{U}$} & \multirow[b]{3}{*}{$\beta^{G}$} & \multirow{2}{*}{\multicolumn{3}{|c|}{$\begin{array}{l}\text { Model parameters } \\
\text { (contagion model) }\end{array}$}} & \multirow[b]{3}{*}{$\gamma^{D}$} & \multirow[b]{3}{*}{$\eta$} \\
\hline & & & & & & & & & & & & & \\
\hline & returns & rank & returns & rank & returns & rank & & & $\beta^{D}$ & $\gamma^{U}$ & $\gamma^{G}$ & & \\
\hline Financial & -55.0 & 1 & -30.6 & 1 & -41.6 & 1 & 0.441 & 0.495 & 0.439 & 0.106 & 0.203 & 0.194 & -0.217 \\
\hline Basic Materials & -53.5 & 2 & -29.1 & 3 & -39.6 & 2 & 0.379 & 0.391 & 0.494 & 0.324 & 0.009 & 0.469 & -0.103 \\
\hline Diversified & -52.4 & 3 & -29.3 & 2 & -35.9 & 3 & 0.477 & 0.433 & 0.709 & 0.157 & 0.037 & 0.163 & -0.045 \\
\hline Consumer, Cycli & -45.7 & 4 & -28.4 & 4 & -34.2 & 4 & 0.386 & 0.379 & 0.519 & 0.096 & 0.039 & 0.232 & -0.068 \\
\hline Industrial & -44.6 & 5 & -24.4 & 8 & -32.5 & 5 & 0.383 & 0.379 & 0.498 & 0.196 & 0.033 & 0.335 & -0.148 \\
\hline Technology & -43.0 & 6 & -27.8 & 5 & -29.2 & 6 & 0.704 & 0.217 & 0.574 & -0.157 & 0.192 & 0.083 & -0.105 \\
\hline Energy & -40.6 & 7 & -27.0 & 7 & -26.8 & 7 & 0.320 & 0.336 & 0.433 & 0.286 & 0.103 & 0.401 & 0.172 \\
\hline Communications & -39.7 & 8 & -27.7 & 6 & -25.6 & 8 & 0.455 & 0.305 & 0.539 & -0.037 & 0.015 & 0.096 & 0.036 \\
\hline Utilities & -35.0 & 9 & -18.6 & 10 & -18.8 & 10 & 0.236 & 0.286 & 0.394 & 0.179 & 0.068 & 0.310 & 0.172 \\
\hline Consumer, Non- & -34.0 & 10 & -22.4 & 9 & -22.2 & 9 & 0.341 & 0.366 & 0.462 & 0.091 & -0.075 & 0.137 & 0.000 \\
\hline
\end{tabular}




\section{Table VI: Contagion and Interdependence}

The table shows the estimates of the following model:

$$
\begin{gathered}
R_{i, t}=E_{t-1}\left[R_{i, t}\right]+\beta_{i, t}{ }^{\prime} F_{t}+\eta_{i, 0} C R_{t}+e_{i, t} \\
\beta_{i, t}=\beta_{i, 0}+\gamma_{i, 0} C R_{t}
\end{gathered}
$$

The table reports estimates of the unweighted average degree of contagion and interdependence across all portfolios in the sample. The critical value of a $\chi^{2}(1)$-distributed variable is $3.84(6.63)$ at the $5 \%(1 \%)$ level. ***, **, and * indicate statistical significance at the $1 \%, 5 \%$, and $10 \%$ levels, respectively.

\section{Benchmark}

\begin{tabular}{|c|c|}
\hline Contagion & \\
\hline$\gamma^{U}$ & $0.133 * * * 0.015$ \\
\hline$\gamma^{G}$ & $0.056 * * \star 0.013$ \\
\hline$\gamma^{D}$ & $0.249 * * * 0.016$ \\
\hline Interdepend & \\
\hline$\beta^{U}$ & $0.397 * * * 0.016$ \\
\hline$\beta^{G}$ & $0.368 * * * 0.012$ \\
\hline$\beta^{D}$ & $0.491 * * * 0.014$ \\
\hline Other & \\
\hline$\eta$ & -0.038 \\
\hline
\end{tabular}

coef st.err.

\section{Test statistics}

Full Sample

ECTEST 27.78

EXCOR

0.06

ECDIAG

459.73

Crisis Period

$\begin{array}{lr}\text { ECTEST } & 0.00 \\ \text { EXCOR } & 0.01 \\ \text { ECDIAG } & 335.94\end{array}$

Observations

322216

R-squared

0.310 


\section{Table VII: Contagion and Interdependence across Regions and Sectors}

The table shows the estimates of the following model:

$$
\begin{gathered}
R_{i, t}=E_{t-1}\left[R_{i, t}\right]+\beta_{i, t}{ }^{\prime} F_{t}+\eta_{i, 0} C R_{t}+e_{i, t} \\
\beta_{i, t}=\beta_{i, 0}+\gamma_{i, 0} C R_{t}
\end{gathered}
$$

The table reports the average contagion and interdependence coefficients across portfolios within a particular region (Panel A), and those within a particular sector (Panel B). ${ }^{* * *},{ }^{* *}$, and * indicate statistical significance at the $1 \%$, $5 \%$, and $10 \%$ levels, respectively.

\begin{tabular}{|c|c|c|c|c|c|c|c|}
\hline \multirow[b]{2}{*}{ Region } & \multicolumn{3}{|c|}{ Contagion } & \multicolumn{3}{|c|}{ Interdependence } & \multirow{2}{*}{$\begin{array}{c}\text { Other } \\
\eta\end{array}$} \\
\hline & $\gamma^{U}$ & $\gamma^{G}$ & $\gamma^{D}$ & $\beta^{U}$ & $\beta^{G}$ & $\beta^{D}$ & \\
\hline Latin America & $0.223 * * *$ & $0.090 * * *$ & $0.212 * \star \star$ & $0.537 * * *$ & $0.305 * \star \star$ & $0.575 * \star \star$ & 0.091 \\
\hline Western Europe & $0.173^{* \star \star}$ & 0.015 & $0.241 * \star \star$ & $0.588 * \star \star$ & $0.509 * \star \star$ & $0.468 * \star *$ & -0.049 \\
\hline Emerging Europe & $0.167^{\star \star \star}$ & $0.109 * \star \star$ & $0.318^{* * *}$ & $0.209 * \star \star$ & $0.281 * \star \star$ & $0.405 * \star \star$ & $-0.160 * \star \star$ \\
\hline Middle East/Africa & -0.038 & 0.082 * & $0.337 * * *$ & $0.092 * * *$ & $0.127 * \star *$ & $0.406 * * \star$ & $0.171 *$ \\
\hline Developed Asia & $0.156 * * *$ & 0.016 & $0.194 * * *$ & $0.455 * * *$ & $0.507 * * *$ & $0.617 * * \star$ & 0.005 \\
\hline Emerging Asia & -0.004 & $0.089 * \star$ & $0.197 * \star \star$ & $0.261 * \star \star$ & $0.324 * \star \star$ & $0.639 * \star \star$ & -0.036 \\
\hline
\end{tabular}

\section{A. By region}

\begin{tabular}{|c|c|c|c|c|c|c|c|}
\hline \multirow[b]{2}{*}{ Sector } & \multicolumn{3}{|c|}{ Contagion } & \multicolumn{3}{|c|}{ Interdependence } & \multirow{2}{*}{$\begin{array}{c}\text { Other } \\
\eta\end{array}$} \\
\hline & $\gamma^{U}$ & $\gamma^{G}$ & & $\beta^{U}$ & $\beta^{G}$ & $\beta^{D}$ & \\
\hline Basic Materials & $0.324 * * *$ & 0.009 & $0.469 * * *$ & $0.379 * * *$ & $0.391 * \star *$ & $0.494 * \star \star$ & -0.103 \\
\hline Communications & -0.037 & 0.015 & $0.096 * * *$ & $0.455 * * *$ & $0.305 * * *$ & $0.539 * * *$ & 0.036 \\
\hline Consumer, Cyclical & $0.096 * \star *$ & 0.039 & $0.232 * * *$ & $0.386 * * *$ & $0.379 * * *$ & $0.519 * * *$ & -0.068 \\
\hline Consumer, Non-cyc| & $0.091 * \star \star$ & $-0.075 * \star \star$ & $0.137 \star \star \star$ & $0.341 * \star *$ & $0.366 * \star \star$ & $0.462 * \star *$ & 0.000 \\
\hline Diversified & 0.157 * & 0.037 & $0.163 * \star *$ & $0.477 * \star *$ & $0.433 * \star \star$ & $0.709 * \star \star$ & -0.045 \\
\hline Energy & $0.286 * \star \star$ & $0.103 * *$ & $0.401 * \star \star$ & $0.320 * \star *$ & $0.336 * \star \star$ & $0.433 * \star \star$ & $0.172 * \star *$ \\
\hline Financial & 0.106 *** & $0.203^{* \star \star}$ & $0.194 * \star \star$ & $0.441 * \star *$ & $0.495 * * *$ & $0.439 * * *$ & $-0.217 * * *$ \\
\hline Industrial & $0.196 * \star \star$ & 0.033 & $0.335 * \star \star$ & $0.383 * \star *$ & $0.379 \star \star \star$ & $0.498 * \star \star$ & -0.148 * \\
\hline Technology & $-0.157 * *$ & $0.192 * \star \star$ & 0.083 & $0.704 * \star *$ & $0.217 * \star \star$ & $0.574 * \star \star$ & -0.105 \\
\hline Utilities & $0.179 * \star \star$ & 0.068 & $0.310 * * *$ & $0.236 * \star *$ & $0.286 * \star \star$ & $0.394 * \star \star$ & $0.172 * * *$ \\
\hline
\end{tabular}

\section{B. By sector}




\section{Table VIII: Correlation Patterns across Contagion and Interdependence Parameters}

The table shows the correlation coefficients across the estimates of the various contagion and interdependence coefficients for the 415 portfolios in the sample, based on the following model:

$$
\begin{gathered}
R_{i, t}=E_{t-1}\left[R_{i, t}\right]+\beta_{i, t}{ }^{\prime} F_{t}+\eta_{i, 0} C R_{t}+e_{i, t} \\
\beta_{i, t}=\beta_{i, 0}+\gamma_{i, 0} C R_{t}
\end{gathered}
$$

$P$-values are shown below the correlation coefficients in smaller figures and italics. Standard errors are based on the

\begin{tabular}{|c|c|c|c|c|c|c|c|}
\hline & \multicolumn{3}{|c|}{ Contagion } & \multicolumn{3}{|c|}{ Interdependence } & \multirow{2}{*}{$\begin{array}{c}\text { Other } \\
\quad \eta\end{array}$} \\
\hline & $\gamma^{U}$ & $\gamma^{G}$ & $\gamma^{D}$ & $\beta^{U}$ & $\beta^{G}$ & $\beta^{D}$ & \\
\hline \multicolumn{8}{|c|}{ Contagion } \\
\hline$\gamma^{U}$ & 1 & & & & & & \\
\hline$\gamma^{G}$ & $\begin{array}{l}0.121 \\
0.013\end{array}$ & 1 & & & & & \\
\hline$\gamma^{D}$ & $\begin{array}{l}0.495 \\
0.000\end{array}$ & $\begin{array}{l}0.219 \\
0.000\end{array}$ & 1 & & & & \\
\hline \multicolumn{8}{|c|}{ Interdependence } \\
\hline$\beta^{U}$ & $\begin{array}{l}2.000 \\
0.000\end{array}$ & $\begin{array}{c}-0.153 \\
0.002\end{array}$ & $\begin{array}{c}-0.306 \\
0.000\end{array}$ & 1 & & & \\
\hline$\beta^{G}$ & $\begin{array}{c}-0.027 \\
0.590\end{array}$ & $\begin{array}{c}-0.273 \\
0.000\end{array}$ & $\begin{array}{c}-0.213 \\
0.000\end{array}$ & $\begin{array}{l}0.620 \\
0.000\end{array}$ & 1 & & \\
\hline$\beta^{D}$ & $\begin{array}{l}-0.276 \\
0.000\end{array}$ & $\begin{array}{c}-0.077 \\
0.119\end{array}$ & $\begin{array}{l}-0.515 \\
0.000\end{array}$ & $\begin{array}{l}0.389 \\
0.000\end{array}$ & $\begin{array}{l}0.319 \\
0.000\end{array}$ & 1 & \\
\hline \multicolumn{8}{|l|}{ Other } \\
\hline$\eta$ & $\begin{array}{l}0.099 \\
0.045\end{array}$ & $\begin{array}{l}0.092 \\
0.061\end{array}$ & $\begin{array}{l}0.084 \\
0.063\end{array}$ & $\begin{array}{l}0.012 \\
0.813\end{array}$ & $\begin{array}{c}-0.018 \\
0.713\end{array}$ & $\begin{array}{c}-0.038 \\
0.438\end{array}$ & 1 \\
\hline
\end{tabular}
cross-sectional distribution of the coefficients. 


\section{Table IX: Diagnostic Tests}

Panel A of the table shows the average increase in correlation with the factor returns during the crisis period in the actual data, and compares it to that produced by the interdependence model and the contagion model, respectively. This is achieved by computing fitted returns from the interdependence model and from the contagion model, and then calculating correlations for each country-sector portfolio with the returns of a benchmark portfolio (the US market, the global market, and the domestic market), for the pre-crisis and the crisis period separately.

Panel B shows a variance ratio analysis. For each factor k (US factor, global factor and domestic factor) we calculate the variance ratio for the fitted returns in the contagion model as

for the interdependence parameters and

$$
\operatorname{VR}_{\beta}^{k}=\frac{\operatorname{cov}\left[\hat{R}_{i, t}, \beta^{k} F_{i, t}^{k}\right]}{\operatorname{var}\left[\hat{R}_{i, t}\right]}
$$

$$
V R_{\gamma}^{k}=\frac{\operatorname{cov}\left[\hat{R}_{i, t}, \gamma^{k} F_{i, t}^{k}\right]}{\operatorname{var}\left[\hat{R}_{i, t}\right]}
$$

for the contagion parameters. Panel B of Table IX presents the averages of the variance ratios across portfolios, for each of the factors, during the crisis period.

\section{A. INCREASE IN CORRELATIONS DURING THE CRISIS}

\begin{tabular}{lccc}
\hline & US & Global & Domestic \\
\hline Actual & 0.171 & 0.197 & 0.082 \\
Predicted (interdependence model) & 0.159 & 0.228 & -0.001 \\
Predicted (contagion model) & 0.170 & 0.220 & 0.049 \\
\hline
\end{tabular}

\section{B. VARIANCE RATIO ANALYSIS}

\begin{tabular}{cccc}
\hline & US & Global & Domestic \\
\hline$\gamma$ & 7.787 & 2.565 & 14.692 \\
$\beta$ & 23.85 & 12.80 & 38.25 \\
\hline
\end{tabular}




\section{Table X: Contagion and Interdependence - Robustness}

The table reports the estimates of the following model:

$$
\begin{gathered}
R_{i, t}=E_{t-1}\left[R_{i, t}\right]+\beta_{i, t}{ }^{\prime} F_{t}+\eta_{i, 0} C R_{t}+e_{i, t} \\
\beta_{i, t}=\beta_{i, 0}+\gamma_{i, 0} C R_{t}
\end{gathered}
$$

The table reports the average contagion and interdependence coefficients across all portfolios in the sample. Results for "Post-Lehman" are based on a definition of the crisis $\left(C R_{\mathrm{t}}=1\right)$ for the period after the Lehman Brothers collapse, i.e. 15 September 2008 - 15 March 2009. "LTCM" crisis takes the period after the collapse of LTCM, from October through December 1998 as the crisis definition, while "TMT bust" defines the decline of global equity markets from October 2000 through December 2002. For these last two estimations, the current crisis observations

\begin{tabular}{|c|c|c|c|c|c|c|c|c|}
\hline & \multicolumn{2}{|c|}{ Benchmark } & \multicolumn{2}{|c|}{ Post-Lehman } & \multicolumn{2}{|c|}{ LTCM crisis } & \multicolumn{2}{|c|}{ TMT bust } \\
\hline & coef & st.err. & coef & st.err. & coef & st.err. & coef & st.err \\
\hline \multicolumn{9}{|l|}{ Contagion } \\
\hline$\gamma^{U}$ & $0.133 * * *$ & 0.015 & $0.142 * * *$ & 0.018 & $-0.026 * * *$ & * 0.002 & $-0.004 *$ & 0.002 \\
\hline$\gamma^{G}$ & $0.056 * * *$ & 0.013 & $0.047 * * *$ & 0.014 & $-0.089 * \star \star$ & 0.019 & 0.010 & 0.013 \\
\hline$\gamma^{D}$ & $0.249 * * *$ & 0.016 & $0.283 * \star \star *$ & 0.021 & -0.030 & 0.030 & -0.013 & 0.026 \\
\hline \multicolumn{9}{|c|}{ Interdependence } \\
\hline$\beta^{U}$ & $0.397 * \star *$ & 0.016 & $0.405 * * *$ & 0.016 & $0.403 * * *$ & * 0.016 & $0.398 * * \star$ & 0.016 \\
\hline$\beta^{G}$ & $0.368 * \star *$ & 0.012 & $0.375 * * *$ & 0.012 & $0.381 * * *$ & * 0.012 & $0.365 * \star *$ & 0.012 \\
\hline$\beta^{D}$ & 0.491 *** & 0.014 & $0.517^{\star \star \star \star}$ & 0.014 & $0.495 * \star *$ & * 0.014 & $0.498 * \star *$ & 0.014 \\
\hline \multicolumn{9}{|l|}{ Other } \\
\hline$\eta$ & -0.038 & 0.025 & -0.148 *** & 0.048 & $-0.179 * \star \star$ & * 0.042 & -0.032 * & 0.018 \\
\hline Observations & \multicolumn{2}{|c|}{322216} & \multicolumn{2}{|c|}{322216} & \multicolumn{2}{|c|}{185223} & \multicolumn{2}{|c|}{185223} \\
\hline R-squared & \multicolumn{2}{|c|}{0.310} & \multicolumn{2}{|c|}{0.348} & \multicolumn{2}{|c|}{0.310} & \multicolumn{2}{|c|}{0.310} \\
\hline
\end{tabular}
are excluded. ${ }^{* * *}, * *$, and $*$ indicate statistical significance at the $1 \%, 5 \%$, and $10 \%$ levels, respectively. 


\section{Table XI: Channels of Contagion - Individual instruments}

The table shows the estimates for the contagion parameters $\gamma$ and the interdependence parameters $\beta$ from the full model (1)-(4), with each variable included individually in each model estimation. ***, **, and *, indicate statistical significance at the $1 \%, 5 \%$, and $10 \%$ levels, respectively. Standard errors are not shown for brevity..

\begin{tabular}{|c|c|c|c|c|c|c|c|}
\hline & \multicolumn{4}{|c|}{ Contagion } & \multicolumn{3}{|c|}{ Interdependence } \\
\hline & US & Global & Domestic & Other & US & Global & Domestic \\
\hline \multicolumn{8}{|l|}{ Banking exposure } \\
\hline Bank exposure to US & $-0.0579 * \star *$ & 0.0172 & $0.0877^{\star \star \star}$ & 0.0162 & $0.0191^{\star \star \star}$ & 0.0104 & 0.0071 \\
\hline Bank exposure to ROW & $-0.0094^{\star * *}$ & 0.0011 & $0.0068^{\star * \star}$ & 0.0046 & $0.0038^{\star \star \star}$ & $0.0029 * * *$ & $0.0029 * * *$ \\
\hline Credit growth & $-0.0058^{\star \star \star}$ & -0.0005 & $0.0017^{*}$ & $0.0227^{\star \star \star}$ & $0.0029 \star \star \star$ & $0.0019 * * *$ & $0.0015^{\star \star \star}$ \\
\hline Interest rate exposure (firm) & $-0.0339 * *$ & 0.0174 & $-0.0600^{\star}$ & 0.0438 & $-0.0808^{\star \star \star}$ & $-0.0668^{\star \star \star}$ & $0.1838^{\star \star *}$ \\
\hline Size & -0.0654 & -0.1246 & 0.1183 & 0.2791 & 0.0392 & 0.0077 & -0.0156 \\
\hline Financial constraint & $-0.0138^{* *}$ & $-0.0212^{\star \star}$ & $0.0141^{\star *}$ & -0.0068 & 0.0024 & 0.0001 & -0.0006 \\
\hline \multicolumn{8}{|l|}{ Banking policy } \\
\hline Debt guarantees & 0.0147 & -0.0144 & $-0.0401^{*}$ & -0.0820 & & & \\
\hline Deposit guarantees & 0.0141 & $-0.2029 *$ & $-0.0389 *$ & -0.0831 & & & \\
\hline Capital injections & 0.0239 & 0.0127 & $-0.1296^{\star \star \star}$ & -0.0663 & & & \\
\hline \multicolumn{8}{|c|}{ External exposure / segmentation: } \\
\hline Portfolio investment flows & $-0.0010^{* * *}$ & 0.0001 & $-0.0009^{\star \star \star}$ & $0.0007^{* *}$ & $0.0008^{\star \star \star}$ & $0.0005^{\star}$ & $0.0007^{\star \star \star}$ \\
\hline Financial integration & $-0.0193^{\star \star \star}$ & $-0.0086^{\star}$ & $-0.0040^{\star *}$ & $0.0225^{\star \star \star}$ & $0.0108^{\star \star \star}$ & $0.0111^{* \star *}$ & $0.0013^{\star \star \star}$ \\
\hline Financial depth & $-0.0013^{\star \star *}$ & $-0.0020 * \star *$ & $-0.0012^{\star \star \star}$ & 0.0002 & $0.0012^{\star \star \star}$ & $0.0018^{* * *}$ & $0.0011^{\star \star *}$ \\
\hline Trade integration & $-0.0038^{\star \star \star}$ & -0.0028 & $-0.0014^{*}$ & $-0.0061^{*}$ & $0.0047^{\star \star \star}$ & $0.0047^{\star * *}$ & $0.0032^{\star \star \star}$ \\
\hline Exchange rate exposure (firm) & $-0.0604^{\star \star \star}$ & $-0.0478^{\star \star}$ & $-0.1389 * * *$ & $0.1390 * \star \star$ & $-0.0899 * \star \star$ & $-0.0764^{\star \star \star}$ & $-0.0871^{\star \star \star}$ \\
\hline \multicolumn{8}{|l|}{ Information asymmetries } \\
\hline Distance & 0.0135 & -0.0295 & & $-0.1501^{\star \star \star}$ & $0.0243^{\star \star \star}$ & $0.0506^{\star \star *}$ & $0.1132^{\star \star *}$ \\
\hline Telephone traffic & -0.0000 & $0.0001^{\star *}$ & & $-0.0002^{*}$ & $0.0000^{* \star \star}$ & $-0.0000^{\star \star}$ & $0.0001^{\star \star \star}$ \\
\hline Newspaper imports & 0.0041 & 0.0153 & & -0.0139 & $0.0658^{\star \star \star}$ & $0.0352^{\star * \star}$ & 0.0079 \\
\hline Difference in opinion & -0.0003 & 0.0001 & -0.0003 & $-0.0023^{\star}$ & 0.0003 & 0.0003 & $0.0006^{\star *}$ \\
\hline \multicolumn{8}{|c|}{ Domestic macroeconomic fundamentals: } \\
\hline Political stability/institutions & $0.0078^{\star * *}$ & -0.0023 & 0.0022 & $0.0667^{\star \star *}$ & $0.0047^{\star \star \star}$ & $0.0030 * *$ & $0.0108^{\star \star *}$ \\
\hline Sovereign rating & $0.0327^{\star * *}$ & -0.0097 & -0.0078 & $0.1132^{\star * \star}$ & $0.0130 * \star \star$ & $0.0125^{\star \star}$ & $0.0385^{\star * \star}$ \\
\hline FX reserves & $-0.0055^{\star \star \star}$ & $-0.0131^{\star \star \star}$ & $-0.0130^{\star \star \star}$ & 0.0021 & $0.0064^{\star \star *}$ & $0.0105^{\star \star *}$ & $0.0152^{\star \star *}$ \\
\hline Current account position & 0.0036 & 0.0054 & $-0.0056^{\star \star *}$ & 0.0001 & $-0.0030 * \star$ & 0.0018 & \\
\hline Unemployment rate & $0.0264^{*}$ & -0.0287 & $0.0560^{\star \star \star}$ & $0.0982^{*}$ & $-0.0182^{\star \star \star}$ & $-0.0166^{\star \star \star}$ & $-0.0125^{\star \star \star}$ \\
\hline Government budget & $-0.0200^{\star * \star}$ & -0.0049 & $-0.0154^{\star * *}$ & 0.0218 & $0.0122^{\star \star \star}$ & $0.0056^{\star *}$ & $0.0047^{\star \star *}$ \\
\hline \multicolumn{8}{|c|}{ Global/common risk and liquidity: } \\
\hline Risk - VIX & $0.0084^{\star * *}$ & $0.0074^{\star * *}$ & $0.0087^{\star * \star}$ & $-0.0050 *$ & $-0.0084^{* * *}$ & $-0.0074^{\star \star \star}$ & $-0.0069 * \star \star$ \\
\hline Credit risk - TED spread & $0.0010^{\star * *}$ & $0.0017^{\star \star *}$ & $0.0010^{\star * *}$ & $-0.0017^{* * *}$ & $-0.0008^{\star \star *}$ & $-0.0016^{\star \star \star}$ & $-0.0010^{\star \star \star}$ \\
\hline
\end{tabular}




\section{Table XII: Channels of Contagion - Encompassing model}

The table shows the estimates for the contagion parameters $\gamma$ and the interdependence parameters $\beta$ from the full model (1)-(4), following the encompassing approach of variable selection described in the text. The approach starts from the full model including all 25 instruments simultaneously, and then step-by-step reducing the model by excluding the variable with the least statistically significant contagion parameter. This procedure is continued until only those instrument variables are left in the model that have significant contagion parameters for a particular factor, at the $10 \%$ significance level.

$* * *, * *$, and *, indicate statistical significance at the $1 \%, 5 \%$, and $10 \%$ levels, respectively. Standard errors are not shown for brevity reasons.

Contagion
Interdependence

US Global Domestic Other US Global Domestic

\section{Banking exposure}

Bank exposure to ROW $\quad-0.003$ ***

Banking policy

Deposit guarantees

Debt guarantees

Capital injections

$-0.138 * * *$

\section{Global Domestic Other}

$-0.004 * *$

$0.006 * \star \star$

External exposure / segmentation:

Portfolio investment flows $\quad-0.008$ ***

$-0.005 * \star *$

$-0.118 * *$

Financial integration

$\begin{array}{lll}-0.145^{* * *} & -0.118 \text { ** } \\ & -0.071^{\star * *} & 0.216 \text { * }\end{array}$

Domestic macroeconomic fundamentals:

Political stability/institutions

Sovereign rating

Current account position

Unemployment rate

$-0.006 * * *$
$0.044 * * *$
$-0.002 * *$

$-0.015 * * * \quad-0.029 * * * \quad-0.055 * * *$

-0.017 *

0.007 ***

$0.027 * \star \star$

0.007

Government budget

$-0.002 * *$

$$
0.003 * \star \star
$$

0.001

0.011 ***

0.014 **

$-0.014 * * *$

0.028 ***
$-0.013 * \star *$

0.002

0.04 *** 


\section{Table XIII: Channels of Contagion - Economic significance in encompassing model}

Based on the encompassing approach of the previous table, this table shows the interquartile ranges, i.e. the difference in the respective interdependence and contagion coefficients for a portfolio with the determinant at its $75^{\text {th }}$ percentile compared with a portfolio at its $25^{\text {th }}$ percentile. The columns labeled "interquartile in crisis" measure this range based on the distribution across portfolios only during the 2007-09 financial crisis, while the columns labeled "interquartile all" use the distribution over the entire (crisis and pre-crisis) sample period.

\begin{tabular}{|c|c|c|c|c|c|c|c|c|c|c|c|}
\hline & \multicolumn{8}{|c|}{ Contagion } & \multirow{2}{*}{\multicolumn{3}{|c|}{$\begin{array}{l}\text { Interdependence } \\
\text { Interquartile all }\end{array}$}} \\
\hline & \multicolumn{4}{|c|}{ Interquartile in crisis } & \multicolumn{4}{|c|}{ Interquartile all } & & & \\
\hline & US & Global & Dom. & Other & US & Global & Dom. & Other & US & Global & Dom. \\
\hline \multicolumn{12}{|l|}{ Banking exposure } \\
\hline Bank exposure to ROW & 0.00 & & & -0.02 & 0.00 & & & -0.02 & 0.00 & & \\
\hline \multicolumn{12}{|l|}{ Banking policy } \\
\hline Deposit guarantees & & & -0.12 & & & & -0.12 & & & & \\
\hline Debt guarantees & & -0.14 & -0.16 & 0.22 & & -0.14 & -0.16 & 0.22 & & & \\
\hline Capital injections & -0.14 & & -0.07 & & -0.14 & & -0.07 & & & & \\
\hline \multicolumn{12}{|c|}{ External exposure / segmentation: } \\
\hline Portfolio investment flows & -0.03 & & 0.02 & & -0.02 & & 0.02 & & 0.06 & & 0.02 \\
\hline Financial integration & -0.17 & & & & -0.08 & & & & 0.06 & & \\
\hline \multicolumn{12}{|c|}{ Domestic macroeconomic fundamentals: } \\
\hline Political stability/institutions & & -0.06 & -0.11 & -0.22 & & -0.07 & -0.14 & -0.28 & & 0.01 & -0.06 \\
\hline Sovereign rating & & -0.17 & & & & -0.17 & & & & 0.11 & \\
\hline Current account position & -0.12 & & & 0.43 & -0.06 & & & 0.37 & 0.15 & & \\
\hline Unemployment rate & 0.17 & & 0.07 & & 0.21 & & 0.09 & & -0.07 & & 0.01 \\
\hline Government budget & -0.02 & & -0.15 & & -0.02 & & -0.11 & & 0.18 & & 0.26 \\
\hline
\end{tabular}




\section{Appendices}

\section{Appendix A. Equity market data and a few stylized facts}

This Appendix outlines the equity market data coverage and definitions and presents a few stylized facts. As the objective is to test for the global transmission of the financial crisis, we use a broad set of 55 countries (other than the United States, which are not included in our analysis of cross-country transmission patterns) that includes not only most of the advanced economies, but also emerging market economies (EMEs) and a few developing countries. Table A.1 lists the country coverage by region. The objective of analyzing the global transmission of the crisis implies that we would like to include stocks of firms that are traded frequently and for which also data on firm-specific characteristics are available. Hence we include only those firms in the analysis that are part of the main equity market index in the respective country, as shown in Table A.1. This comprises about 2,000 firms in total, for which we have extracted daily equity returns in US dollars. ${ }^{13}$

Table A.1

From the firm-level data we construct country-sector portfolios, using the Bloomberg classification that allocates firms into 10 broad industry sectors. This yields in total 415 country-industry or country-sector portfolios. Not every of the 55 countries in the sample has therefore 10 country-sector portfolios as not all countries have firms in each of the 10 sectors in their main stock market index. These portfolios are value-weighted, so that each firm is weighted according to its relative market capitalization in its respective portfolio. While the number of firms included in a portfolio can be small (and indeed, for some of the smallest countries with a low number of listed firms, a single firm may represent an entire sector), our procedure restricts attention to relatively large firms in each country for which we have reliable data.

As to the current financial crisis, we define the starting point of the crisis as August 7, 2007, when equity markets initially fell and central banks started intervening for the first time to provide liquidity to financial markets. The last observation in our dataset is 15 March 2009. An alternative crisis definition is to start with the bankruptcy of Lehman Brothers on September 15, 2008, which we 
investigate as a robustness check. Using our data to compute world market returns, the crisis meant an equity market decline of about 50\% from peak to trough, occurring in about 18 months (from mid-2007 to early 2009).

\section{Appendix B. Portfolio-specific determinants}

In addition to the country-specific and common/global instruments outlined in section I, we control for a number of portfolio-specific determinants of crisis vulnerability. Specifically, we are interested in capturing two potential channels: financial constraints and external exposures at the firm level. There is a large literature in monetary economics and in finance on how to measure the degree of financial constraints faced by firms (see e.g. Almeida et al. 2004; Whited and Wu 2006). We follow the approach used by Whited and Wu (2006) and define financial constraints of a particular firm in the following way:

$$
F C_{i, t}=-0.09 C F_{i, t}-0.062 D D_{i, t}+0.02 D A_{i, t}-0.044 \ln A_{i, t}+0.10 I G_{i, t}-0.035 F G_{i, t}
$$

with $C F$ as the cash flow-net asset ratio, $D D$ a firm's dividend payments, $D A$ the debt-net assets ratio, $A$ total net assets, $I G$ industry growth rate, and $F G$ as the firm's growth rate in net assets. A related exposure is a firm's exposure to changes in the cost of financing. Similar to the estimation proposed by Ammer, Vega and Wongswan (2008), we measure this channel as the interest rate exposure of individual portfolios to changes in domestic three-month interest rates, $\Delta r_{i, t}$, in the following way:

$$
R_{i, t}=\eta_{0}+\varphi_{i} \Delta r_{i, t}+\kappa_{i} R_{t}^{U S}+e_{i, t}
$$

using weekly data, in order to obtain portfolio-specific interest rate exposures $\varphi_{i}$. Unfortunately, shortterm interest rates at weekly frequencies are not available for all countries so that the sample size is more limited for this interest rate exposure variable, and a few portfolios drop out from the sample.

Turning to proxies of firm-level external exposure, the exchange rate exposure of firms has been stressed in the literature as an important reason for why firms' equity valuations are affected by foreign shocks (e.g. Adler and Dumas 1984, Dominguez and Tesar 2001 and 2006). The rationale is as follows: a firm is likely to be more strongly affected by a particular US shock and the resulting exchange rate change if it has a high external exposure, e.g. via trade or via external financial linkages. Following the 
methodology proposed by Dominguez and Tesar (2001), we proxy the exchange rate exposure of each portfolio to the United States by the sensitivity of its excess equity return at time $t, R_{i, t}$, to bilateral exchange rate changes vis-à-vis the US dollar, $\Delta s_{i, t}$, controlling in the estimation also for US equity returns $R_{t}^{U S}$ :

$$
R_{i, t}=\delta_{0}+\delta_{i} \Delta s_{i, t}+\kappa_{i} R_{t}^{U S}+e_{i, t}
$$

where the exchange rate exposure for each portfolio, estimated over the whole pre-crisis sample period 1 January 1995 to 6 August 2007, is measured as $\delta_{i}$. For the estimation we use weekly data. 


\section{Table A.1: Country sample and equity indices}

The 10 broad industry sectors taken from Bloomberg's classification used to create the market-weighted countrysector equity portfolios are: (i) basic materials, (ii) communications, (iii) consumer cyclical goods, (iv) consumer non-cyclical goods, (v) diversified, (vi) energy, (vii) financials, (viii) industrial, (ix) technology and (x) utilities. For the US, the stock index used is the S\&P 500 .

\begin{tabular}{|c|c|c|c|c|c|}
\hline Country & $\begin{array}{l}\text { Name of stock } \\
\text { index }\end{array}$ & $\begin{array}{l}\text { No. listed } \\
\text { firms }\end{array}$ & Country & $\begin{array}{c}\text { Name of stock } \\
\text { index }\end{array}$ & $\begin{array}{l}\text { No. listed } \\
\text { firms }\end{array}$ \\
\hline \multicolumn{3}{|c|}{ Industrialised } & \multicolumn{3}{|c|}{ Emerging Europe } \\
\hline Australia & S\&P ASX & 30 & Bulgaria & SOFIX & 20 \\
\hline Austria & ATX & 20 & Croatia & CROBEX & 28 \\
\hline Belgium & BEL20 & 20 & Czech Republic & PSE & 14 \\
\hline Canada & S\&P TSE 60 & 60 & Estonia & OMX & 18 \\
\hline Denmark & OMX20 & 20 & Hungary & BSE & 14 \\
\hline Finland & OMX25 & 25 & Latvia & OMX & 35 \\
\hline France & CAC 40 & 40 & Malta & MSE & 19 \\
\hline Germany & DAX & 30 & Lithuania & OMX & 32 \\
\hline Iceland & OMX ICEX & 11 & Poland & WIG 20 & 20 \\
\hline Ireland & ISEQ & 60 & Romania & BET & 10 \\
\hline Italy & MIB 30 & 30 & Russia & MICEX & 30 \\
\hline Japan & Topix 70 & 70 & Serbia & Belex 15 & 15 \\
\hline Luxembourg & LuxX & 9 & Slovenia & SBI & 15 \\
\hline Netherlands & AEX & 25 & Turkey & ISE National 30 & 30 \\
\hline Norway & OBX & 24 & Ukraine & PFTS & 19 \\
\hline Portugal & PSI 20 & 20 & & & \\
\hline Slovenia & SBI & 15 & & dle-East and Africa & \\
\hline Spain & IBEX 35 & 35 & & & \\
\hline Sweden & OMX 30 & 30 & Egypt & CASE & 30 \\
\hline Switzerland & SMI & 20 & Israel & Tel Aviv-25 & 25 \\
\hline \multirow[t]{3}{*}{ UK } & Footsie 100 & 100 & Qatar & $\mathrm{QE}$ & 20 \\
\hline & & & Tunisia & SE BVMT & 32 \\
\hline & Asia-Pacific & & UAE & DFM & 29 \\
\hline China & Shanghai SE 50 & 50 & & & \\
\hline Hong Kong & Hang Seng & 42 & \multicolumn{3}{|c|}{ Latin America } \\
\hline India & BSE Sensex 30 & 30 & & & \\
\hline Indonesia & Jakarta LQ-45 & 45 & Argentina & Merval & 22 \\
\hline Korea & Kospi 50 & 50 & Brazil & Bovespa & 66 \\
\hline New Zealand & NZX 15 & 15 & Chile & IPSA & 40 \\
\hline Singapore & Strait Times & 30 & Colombia & IGBC General & 28 \\
\hline Taiwan & TSEC Taiwan 50 & 50 & Mexico & Bolsa & 36 \\
\hline Thailand & SET 50 & 50 & & & \\
\hline
\end{tabular}

Source: Bloomberg. 


\section{Endnotes}

1 Pukthuanthong and Roll (2009) stress that decreases in idiosyncratic volatility can also induce excess comovements.

${ }^{2}$ This term was coined by Goldstein (1998) in the wake of the Asian financial crisis, with the Thai currency crisis of 1997 acting as a "wake-up call” for international investors who eventually recognised that the so-called "Asian miracle” of the time was rather an "Asian mirage”, which ultimately led to a reassessment of the creditworthiness of Hong Kong, Indonesia, Korea, Malaysia and Singapore.

${ }^{3}$ Whereas the imperfect integration of emerging markets into global capital markets is well-known (see for instance Bekaert and Harvey (1997), or Carrieri, Errunza and Hogan (2007)), the analysis in Bekaert, Hodrick and Zhang (2009), Bodnar, Dumas and Marston (2003) and Brooks and Del Negro (2006) motivates the use of both global/international and domestic factors from a statistical perspective, even for developed markets.

${ }^{4}$ We have also estimated the model in local currency excess returns with qualitatively similar results.

${ }^{5}$ Note that this orthogonalization is quite independent relative to the precise time period over which it is done. For instance, orthogonalizing separately for the crisis and non-crisis periods yields very similar factors as the orthogonalization over the entire sample period.

${ }^{6}$ More specifically, the orthogonalized domestic factor is estimated for each country-sector portfolio $i$ individually as portfolio $i$ itself is excluded from the domestic market portfolio.

${ }^{7}$ Note that we do not mean to suggest that these "instruments" are 'exogenous" in the strict sense of econometric identification. In the asset pricing literature, as for instance discussed in Ferson and Harvey (1991), this term is simply used for variables that are not returns and are pre-determined (in a temporal sense) and used to model timevariation in factor exposures or prices of risk.

${ }^{8}$ King (2009) uses these data in an event study to investigate the effect of such policies on the pricing of bonds and equities of domestic financial and non-financial institutions.

${ }^{9}$ In almost all cases such policies were still in existence at the end of our sample. We prefer to use the policy announcement, rather than the actual implementation - which in many cases took several weeks after the announcement - in order to capture the expectations effect of such policies on financial markets. Moreover, we prefer to use dummies rather than measures of the magnitude of deposit and debt guarantees and capital injections, primarily in order to obtain measures that are comparable across countries, as it is otherwise difficult to normalize and compare magnitudes of such measures in a meaningful way. 
${ }^{10}$ We also pursued another direction, namely by extracting principal components for each of the six categories of instruments outlined above. We then use the first principal components in the model estimation which mostly capture more than $60 \%$ of the variation of the underlying variables, in the model estimation. One crucial drawback of the principal component analysis is that some principal components themselves are hard to interpret economically, which means that not only the sign of the relationship but also the economic relevance of the different channels are hard to gauge. Nevertheless, the findings are consistent with those of the encompassing model. Results for the principal component analysis are available upon request.

${ }^{11}$ More specifically, the series of weekly predicted returns is used to create a fitted price index, from which in turn the total return over the entire sample period is calculated.

${ }^{12}$ We also compute a variance ratio for the $\eta$-part of the model, but find this to be unimportant, hence do not report it in Table IX.

${ }^{13}$ The analysis is therefore from the perspective of a US investor. Note that equity returns in US dollar terms have been even more negative during the crisis given that almost all currencies (bar the Japanese yen, and a few pegged currencies) depreciated against the US dollar; see Fratzscher (2009). 